\title{
Early non-social behavioural indicators of autism spectrum disorder (ASD) in siblings at elevated likelihood for ASD: a systematic review
}

\author{
Daniela Canu ${ }^{1,2,3}$ (D) Sara Van der Paelt ${ }^{2} \cdot$ Ricardo Canal-Bedia $^{4} \cdot$ Manuel Posada $^{5} \cdot$ Marleen Vanvuchelen $^{1}$. \\ Herbert Roeyers ${ }^{2}$
}

Received: 12 October 2019 / Accepted: 31 January 2020 / Published online: 22 February 2020

(c) The Author(s) 2020

\begin{abstract}
We aimed at identifying early non-social behavioural indicators that predict later ASD. Likewise, we were interested in the moment in which non-social signs discriminate between children at elevated likelihood for ASD with a later diagnosis of ASD, and children at elevated likelihood for ASD with a typical developmental outcome. In addition, we intended to explore the developmental evolution of children's symptomatology over time. A systematic literature search was conducted for longitudinal studies on early non-social behavioural indicators among siblings at elevated likelihood for ASD. The following databases were searched: PUBMED, Web of Science, PsycINFO, CINAHL and EMBASE. The study identification process was conducted by two reviewers independently. Compared to siblings at elevated likelihood for ASD with a typical developmental outcome, siblings at elevated likelihood for ASD with later ASD show impairments in attention disengagement, in gross and fine motor development and characteristic restricted and repetitive interests and behaviours, starting at 12 months of age. Moreover, early attention disengagement exerts a predictive role towards a later ASD diagnosis, given that from 12 months siblings at elevated likelihood for ASD who will receive an independent ASD diagnosis towards 24-36 months present marked difficulties in disengaging in comparison with siblings at elevated likelihood for ASD that will not satisfy the criteria for an ASD diagnosis. The findings call for a more comprehensive vision on early indicators of ASD. Further research is needed to extend results to other behavioural domains.
\end{abstract}

Keywords Autism spectrum disorder · Siblings at elevated likelihood for ASD · Early signs · Non-social behaviours · Systematic review

Electronic supplementary material The online version of this article (https://doi.org/10.1007/s00787-020-01487-7) contains supplementary material, which is available to authorized users.

Daniela Canu

daniela.canu@uniklinik-freiburg.de

1 Faculty of Rehabilitation Sciences, Rehabilitation Research Center (REVAL), Hasselt Unversity, Agoralaan, Building A, 3590 Diepenbeek, Hasselt, Belgium

2 Research in Developmental Disorders Lab, Department of Experimental Clinical and Health Psychology, Ghent University, Ghent, Belgium

3 Clinic for Child and Adolescent Psychiatry, Psychotherapy and Psychosomatics, Medical Center - University of Freiburg, Faculty of Medicine, University of Freiburg, Freiburg, Germany

4 Instituto Universitario de Integración en la Comunidad (INICO), University of Salamanca, Salamanca, Spain

5 Institute of Rare Diseases Research \& CIBERER, Instituto de Salud Carlos III, Madrid, Spain

\section{Introduction}

Autism spectrum disorder (ASD) is a neurodevelopmental disorder defined by a pattern of persistent impairments in social interaction and social communication across several contexts, together with narrow, stereotyped, repetitive behaviour [1]. Estimates of its prevalence vary from $1 \%$ [1,2] to $1.5 \%$ [3] amongst the general population. The rate increases up to $18.7 \%$ [4] amongst younger siblings of children with ASD, considered at elevated likelihood for ASD (EL), suggesting a strong genetic contribution [5]. An early diagnosis of ASD can have a positive impact on children's developmental outcome [6]. However, many of these children experience diagnostic delays [7]. Therefore, the average diagnostic age ranges between 38 and 120 months [8]. This finding is surprising, given that the majority of parents express their concerns before their child's second birthday [9]. 
To shorten this temporal gap between parents' first concerns and clinical diagnosis, a significant effort has been made. A vast majority of studies has identified some precursors of social interaction and communication deficits. Decreased frequency of orientation to social stimuli, complex babbling, word production, gesture use and imitation are among the most common early signs, which often appear late in the first year $[10,11]$. However, clear discrepancies in the social domain become more obvious by 18-24 months of age [12]. The majority of cognitive theories coming from these results propose a single initial impairment in social information processing or in social orienting (i.e. theory of mind; [13], social orienting; [14]).

More recently, growing literature is emerging on nonsocial behavioural indicators, due to the inability of social theories to fully cover the complex variety of the spectrum. Hence, new theorizations on the development of ASD have been proposed. Among them the model of domain general impairment, the cascade models and the cumulative models are particularly promising. According to the model of domain general impairment, gaze abnormalities in ASD are not unique to the social domain. On the contrary, they indicate a more basic attention deficit that, in turn, affects socio-communicative development [15]. Although referring to attention, this concept can easily be generalized to any non-social feature. This model paves the way for the possibility that non-social features are visible early in children's development and before the social impairments are clearly manifested $[15,16]$. If this is the case, we could identify ASD in EL children at an earlier age. The cumulative models state that brain systems subserving social and non-social cognition contribute to ASD via separate pathways [15, 17]. Cascade effect models imply interactions between different factors during development [15]. Despite the differences, these models represent an attempt to better describe the variability and complexity of people with ASD.

The present review seeks to supplement the wide literature on social indicators with the necessary insight regarding the non-social impairments of young children with later ASD. To our knowledge, this is the first systematic review to selectively focus on early non-social behavioural indicators of ASD in EL siblings, through a systematic comparison with younger siblings of children with a typical development, considered at typical likelihood for ASD (TL). Previous attempts have combined behavioural and biological signs as well as pre-, peri- and post-natal indicators of ASD in populations at elevated risk for ASD [18, 19]. In other cases, they included the whole range of behavioural indicators [20-22]. Alternatively, some reviews have selectively focused on a single behavioural domain. Examples are Sacrey et al. [23] about attention disengagement in EL children, Downey and Rapport [24] about impaired motor activity in children who later develop ASD and Leekam et al.
[25] about repetitive and restricted behaviours in children with ASD. The cited reviews recognize that non-social signs are systematically evident within the ASD spectrum. Sacrey et al. [23] identified attention disengagement as an early marker of ASD, being atypical in the first year of life. No link between disengagement and other attention components has been explored, nor have studies assessed disengagement in complex, ecological settings. Downey and Rapport [24] concluded that motor abnormality is an observable trend in children with ASD. Nevertheless, the authors did not report specific motor patterns or explore the developmental moment in which motor abnormalities appeared. According to Leekam et al. [25], restricted and repetitive behaviours in ASD versus other clinical conditions did not differ in their systematic form or pattern, but rather in their frequency. Children with ASD present restricted and repetitive interests across a wide range of behaviours, while in other disorders they seem to be more specific to a single domain (for example only obsessions and compulsions in Obsessive Compulsive Disorder, hoarding in Prader-Willi syndrome). Finally, the frequency of repetitive and restricted behaviours is affected by age and developmental level in ASD.

The aims of the present review were: to summarize the state of the art on early non-social behavioural indicators of ASD that are able to discriminate between EL and TL samples, as well as within the EL sample; to identify at what age EL subgroups differ in various non-social domains and to explore whether early non-social behaviours are good predictors for a later ASD diagnosis, thus clarifying the nature of this association and describing the developmental evolution over time.

\section{Methods}

\section{Study design}

A literature search was conducted using the databases PUBMED, Web of Science, PsycINFO, CINAHL and EMBASE. The search terms were defined through a combination of $\mathrm{MeSH}$ terms and terms chosen mutually by two reviewers (the first and second author of this review). Additionally, eligible studies were searched for by manually examining the reference list of other reviews. The search strategy is provided in Fig. 1.

\section{Study criteria}

For each database, the search was limited to studies published in English between January 1, 2005 and April 15, 2019, thus covering the last 15 years of research on EL siblings since sufficient consensus on the core symptoms of ASD had been reached. The risk of bias was controlled 
Fig. 1 Keywords with mapped medical subject headings (MeSH) terms

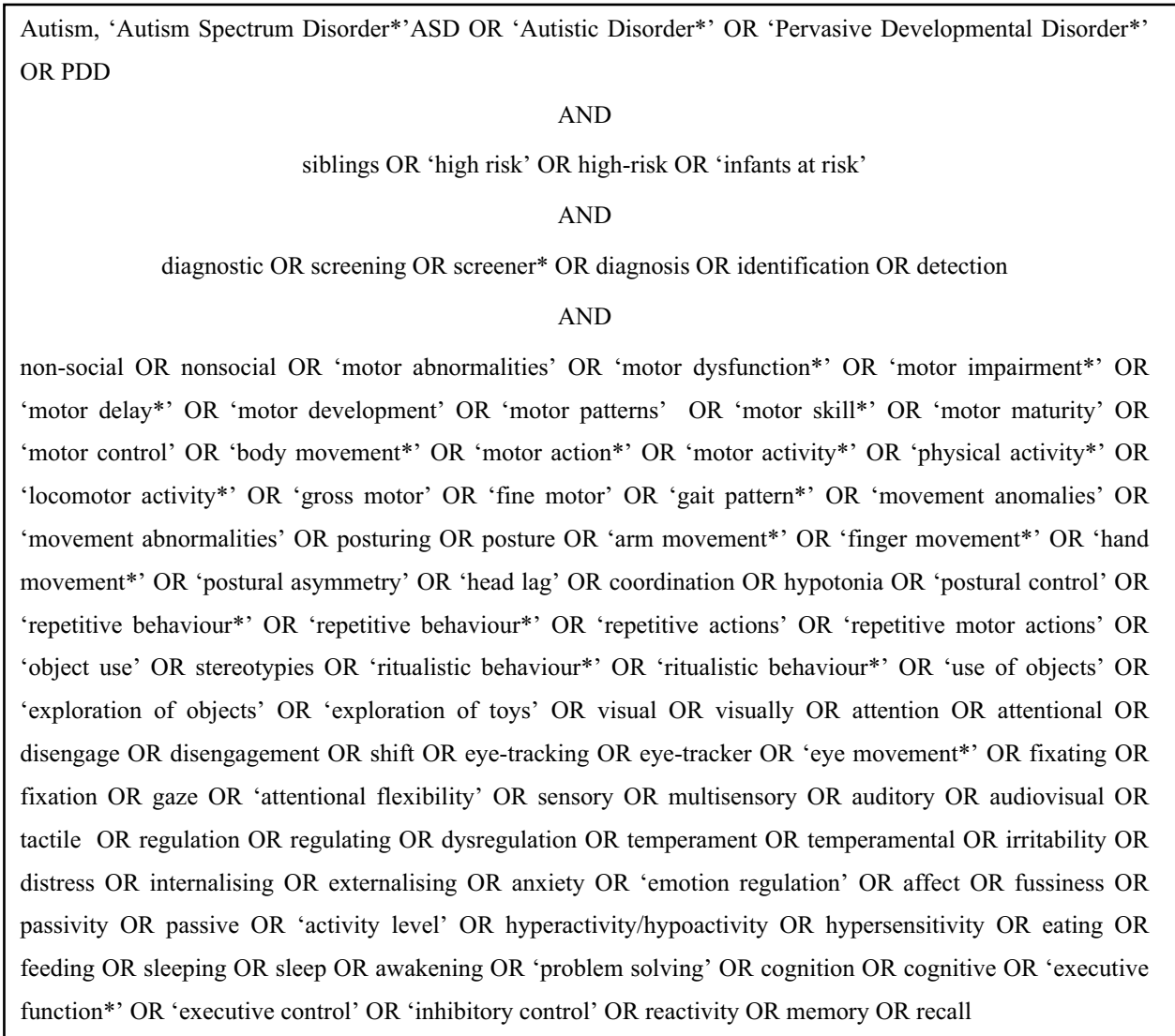

already at a study level by defining strict inclusion and exclusion criteria prior to the beginning of the search process.

Eligible studies were longitudinal studies on EL children, more specifically younger siblings of children with ASD. We included studies on children aged 36 months at the latest, at the moment of their first assessment. Studies were selected if children were followed up until a diagnostic indication was made. Overall, across all studies EL participants were separated into three subgroups: children with ASD (ELASD), children with developmental delay (EL-Other) and children with a typical outcome (EL-TD). In two studies EL participants were stratified according to the severity of the autistic symptoms: EL-Autism, with higher ADOS scores (above autism cut-off), EL-ASD, with lower ADOS scores (above ASD cut-off, but below autism cut-off), and EL-TD with ADOS scores below ASD cut-off [26, 27].

In regard to our domain of interest, the search was restricted to non-social behaviours. With the non-social attribute we referred to observable behaviours (motor behaviour, repetitive/stereotyped behaviour, play and sensory behaviour) but also cognitive functions (attention, executive functioning), and personal characteristics (temperament), which do not activate any social competency and do not imply an interaction with another person.
As part of the non-social behavioural manifestations of ASD, we also included studies assessing participants' attention towards social stimuli, provided that this cognitive competency was not assessed during social interaction. Examples are studies on preference towards social versus non-social stimuli, on the ability to recognize social stimuli (i.e. faces) and on free viewing of social scenes.

As for their contextual relevance, papers that explored the predictive role of non-social behavioural characteristics towards a later ASD diagnosis and studies assessing whether non-social behavioural features discriminated between clinical and control groups were included.

In line with the above, we excluded studies with premature infants, born before 32 weeks of gestation, as early prematurity is associated with increased risk for ASD [28]. Only one study [29] included participants (3 out of $50 \mathrm{TL}$ participants) born between 32 and 34 weeks gestational age. Similarly, we excluded studies with infants that at the time of enrollment were affected by or had an older sibling or a first-degree relative with any known genetic or chromosomal syndrome or neurological disorder that could account for ASD or any other disorder known to often be in comorbidity with ASD (i.e. psychosis, schizophrenia, bipolar disorder). Such a decision was motivated by our confined interest in 
exploring early ASD indicators in EL infants, whose EL status comes uniquely from having an older sibling with ASD. Conversely, we did not aim at exploring early indicators of ASD, in which the ASD diagnosis is consequent to genetic, chromosomal or neurologic conditions, or due to a family member affected by another psychiatric disorder, all representing separate risk factors for ASD. We additionally excluded studies focused on biomarkers of ASD, given that the review focused selectively on the phenotypic characterization of ASD, but also studies that compared early indicators of ASD and other clinical conditions, as it was not a goal of the present review to identify atypical behaviours common to ASD and other disorders. Finally, studies in which the diagnostic indication was not mentioned were not considered in the final selection, since they prevented any conclusion to be reached.

\section{Data extraction and study quality evaluation}

Information was extracted from each included article on: name of first author, publication date, type of study design, characteristics of participants (including age, presence of older sibling with ASD diagnosis, method for assessing ASD diagnosis), type of assessed behaviour, method for assessing behaviour, type of follow-up, type of outcome measures.

To ascertain the validity of eligible longitudinal studies the two reviewers worked independently. Additionally, several titles, abstracts and full texts were reviewed twice, whenever disagreement emerged. Disagreements were resolved by detailed discussion until a consensus evaluation on all articles was reached, guaranteeing a reliability above $90 \%$.

Furthermore, all included studies were assessed for methodological features most relevant for the control of bias. The risk of bias was measured at a study level, and independently by the two reviewers, using the Newcastle-Ottawa Scale for evaluating the quality of nonrandomized studies (NOS; [30]). Three factors were taken into account: selection, indicating the representativeness of the exposed cohort (EL group) as well as the ascertainment that exposed and non-exposed (TL group) cohorts belonged to the same community; comparability, assessing whether confounding variables were adjusted for; outcome, based on the duration and completeness of the follow-up period, and ascertained through adequate assessment (expert clinical judgment using standardized diagnostic instruments).

In line with the guidelines of the NOS, "good" quality score required 3 or 4 stars in selection, 1 or 2 stars in comparability, and 2 or 3 stars in outcome, "fair" quality score required 2 stars in selection, 1 or 2 stars in comparability, and 2 or 3 stars in outcomes, "poor" quality score implied 0 or $1 \mathrm{star}(\mathrm{s})$ in selection, or 0 stars in comparability, or 0 or 1 star(s) in outcomes.

\section{Articles' identification process}

The initial database search yielded 4618 articles. After removing the duplicates 3680 articles remained. In the following stages the two independent reviewers screened titles and abstracts for eligibility. After title screening 166 articles remained. In this phase, abstracts were inspected for all articles that appeared to be related to the subject. A total of 58 abstracts met the inclusion criteria. 38 articles were included in the systematic review after a close reading of the full texts. For a more schematic representation of the process, implemented according to the PRISMA guidelines, see Fig. 2.

\section{Results}

Through the application of the NOS guidelines, 31 studies were scored as "good", 7 studies as "fair", 1 study as "poor". This last study was excluded from further examination. Details on the evaluation of risk of bias for each study are reported in the Table in the supplementary material.

Through data extraction, eight behavioural domains were identified within the 38 included studies: attention ( $n=15)$, visual processing $(n=6)$, executive functioning $(n=1)$, motor functioning $(n=11)$, repetitive/stereotyped behaviour $(n=5)$, sensory processing $(n=5)$, play $(n=2)$ and temperament $(n=6)$. Ten out of 38 studies explored at least two behavioural domains, the remaining focused on a single domain. Results will be presented separately for each domain. A synthetic description of the experimental design, participants, instruments and results for every study can be found in Table 1 and, separately for each domain, in Tables 2, 3, 4, 5, 6, 7, 8 and 9. Summary outcome measures are between-group differences in the aforementioned dimensions (i.e. first EL versus TL, and next EL-ASD versus EL-TD and EL-Other), their predictive role towards later ASD diagnosis, and their developmental evolution over time. Findings on a non-social domain are accounted as consistent if concordant results are reported by at least two articles, from different research groups. Additionally, specifications on the assessment instrument of non-social behaviour are provided when describing both concordant and discordant findings.

\section{Attention $(n=15$; Table 2)}

The vast number of studies covered seven aspects or subcomponents of attention development: disengagement of attention, attention shift and engagement, visual tracking, sustained attention, saccadic inhibitory control, visual search, and social attention without social interaction. 
Fig. 2 PRISMA flowchart of retrieved studies

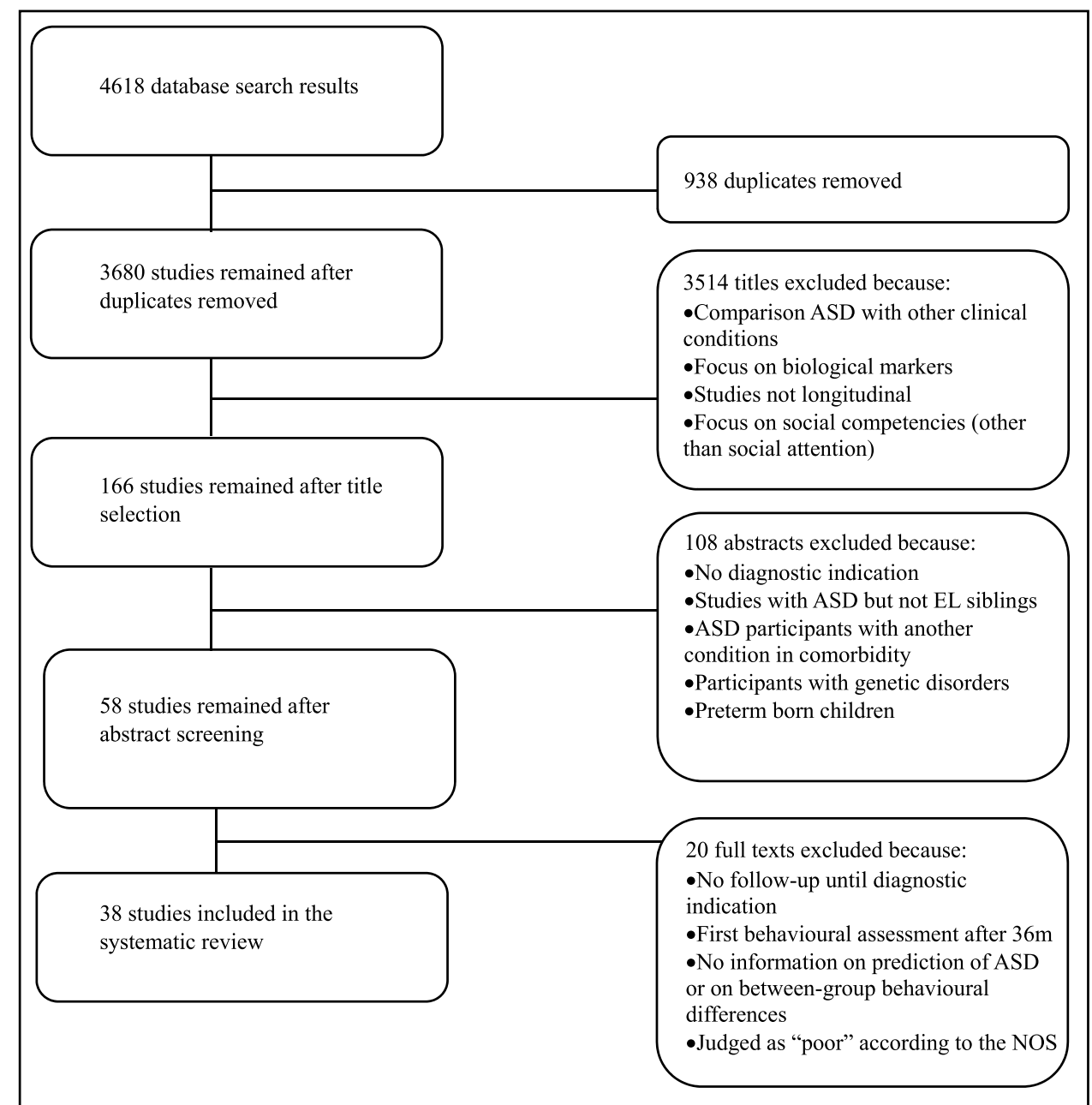

\section{Disengagement of attention $(n=5)$}

Attention disengagement was explored through a visual orienting task in three studies [31, 32, 59] various play situations in one study [62], and using both a visual orienting task and a play situation in one study [33]. In the visual orienting task, a stimulus is presented on the right or left of the screen while the participant is looking at a central stimulus. Three trial types can alternate: the overlap condition in which the central fixation and the peripheral stimulus are extinguished simultaneously, the gap condition, in which the central fixation extinguishes before the peripheral stimulus appears and the baseline condition in which the central fixation stimulus extinguishes as soon as the peripheral stimulus appears. Two out of four studies [31, 59] included overlap and baseline conditions, the remaining [32,33] considered overlap and gap conditions. Attention disengagement was conceptualised, across studies, as the latency to make an eye movement towards a peripheral stimulus while the subject is engaged on a central fixation stimulus [31, 32, 59]. In Bedford et al. [31] and Elsabbagh et al. [59], disengagement was calculated as the difference between the saccadic reaction time in overlap trials compared to baseline trials. Zwaigenbaum et al. [33] additionally explored the construct during a play situation from the Autism Observation Scale for Infants (AOSI; [65]), while Sacrey et al. [62] analysed play situations from both the AOSI and the Autism Diagnostic Observation Schedule (ADOS; [66]). The AOSI [65] is an observational measure based on a standard set of semi-structured activities, developed to detect early signs of autism as they emerge in EL infants. Attention disengagement is explored by shaking a rattle on one side of the infant while his attention is engaged on another rattle that has been previously presented on his other side. The ADOS [66] uses standardized activities to elicit communication, social interaction, imaginative use of play materials and repetitive behaviours. It assesses disengagement via looking at the time period between the target's grasp and an eye movement away from the target. Results from the visual orienting task revealed that disengagement discriminated EL from TL between 6 and 12 months [33]. From the end of children's first year and during the second year, differences were visible within the 
Table 1 Summary of the results

\begin{tabular}{|c|c|c|c|c|}
\hline Domain & Sub-domain & $\begin{array}{l}\text { Differences between EL-ASD and } \\
\text { EL-TD }\end{array}$ & Age of appearance & Main papers reporting results \\
\hline \multirow[t]{19}{*}{ Attention } & Disengagement of attention & $\begin{array}{l}\text { Disengagement of attention predictor } \\
\text { of ASD }\end{array}$ & $12-13$ months & $\begin{array}{l}\text { Bedford et al. [31], Bryson } \\
\text { et al. [32], Zwaigenbaum } \\
\text { et al. [33] }\end{array}$ \\
\hline & Attention engagement & $\begin{array}{l}\text { No significant between-group differ- } \\
\text { ence }\end{array}$ & - & $\begin{array}{l}\text { Sacrey et al. [19], Gammer } \\
\text { et al. [29] }\end{array}$ \\
\hline & Attention shift & $\begin{array}{l}\text { No significant between-group differ- } \\
\text { ence }\end{array}$ & - & $\begin{array}{l}\text { Bryson et al. [32], Zwaigen- } \\
\text { baum et al. [33] }\end{array}$ \\
\hline & \multirow[t]{3}{*}{ Visual tracking } & Inconclusive results: & & \\
\hline & & $\begin{array}{l}\text { No significant between-group differ- } \\
\text { ence versus }\end{array}$ & - & Gammer et al. [29] \\
\hline & & Visual tracking predictor of ASD & 12 months & Zwaigenbaum et al. [33] \\
\hline & \multirow[t]{3}{*}{ Sustained attention } & Inconclusive results: & & \\
\hline & & $\begin{array}{l}\text { Significant between-group difference } \\
\text { versus }\end{array}$ & 12 months & Zwaigenbaum et al. [33] \\
\hline & & $\begin{array}{l}\text { No significant between-group differ- } \\
\text { ence }\end{array}$ & - & Wass et al. [34] \\
\hline & \multirow[t]{2}{*}{ Saccadic inhibitory control } & Inconclusive results (1 study): & & \\
\hline & & $\begin{array}{l}\text { No significant between-group differ- } \\
\text { ence }\end{array}$ & - & Pijl et al. [35] \\
\hline & \multirow[t]{3}{*}{ Visual search } & Inconclusive results: & & \\
\hline & & $\begin{array}{l}\text { Visual search predictor of ASD } \\
\text { versus }\end{array}$ & 15 months, 2 years & Gammer et al. [29] \\
\hline & & $\begin{array}{l}\text { No significant between-group differ- } \\
\text { ence }\end{array}$ & - & Cheung et al. [36] \\
\hline & \multirow{5}{*}{$\begin{array}{l}\text { Social Attention without } \\
\text { social interaction }\end{array}$} & Inconclusive results: & & \\
\hline & & $\begin{array}{l}\text { 1. Face processing: } \\
\text { Predictor of ASD versus }\end{array}$ & 14 months & de Klerk et al. [37] \\
\hline & & $\begin{array}{l}\text { No significant between-group dif- } \\
\text { ference }\end{array}$ & - & Rutherford et al. [38] \\
\hline & & $\begin{array}{l}\text { 2. Gaze following behaviour: } \\
\text { Significant between-group difference }\end{array}$ & 13 months & Bedford et al. [39] \\
\hline & & $\begin{array}{l}\text { 3. Perception of biological motion: } \\
\text { No significant between-group dif- } \\
\text { ference }\end{array}$ & - & Falck-Ytter et al. [40] \\
\hline \multirow[t]{3}{*}{ Visual processing } & \multirow[t]{3}{*}{-} & Inconclusive results: & & \\
\hline & & $\begin{array}{l}\text { Significant between-group difference } \\
\text { versus }\end{array}$ & $\begin{array}{l}\text { From } 14 \text { months } \\
\text { on }\end{array}$ & Landa et al. [41] \\
\hline & & $\begin{array}{l}\text { No significant between-group differ- } \\
\text { ence }\end{array}$ & - & $\begin{array}{l}\text { Libertus et al. [42], Kaur } \\
\text { et al. [43], Germani et al. } \\
\text { [44] }\end{array}$ \\
\hline \multirow[t]{4}{*}{ Executive functioning } & \multirow[t]{2}{*}{ Working memory } & Inconclusive results (1study): & & \\
\hline & & $\begin{array}{l}\text { No significant between-group differ- } \\
\text { ence }\end{array}$ & - & St. John et al. [45] \\
\hline & \multirow[t]{2}{*}{ Response inhibition } & Inconclusive results (1study): & & \\
\hline & & $\begin{array}{l}\text { No significant between-group differ- } \\
\text { ence }\end{array}$ & - & St. John et al. [45] \\
\hline
\end{tabular}


Table 1 (continued)

\begin{tabular}{|c|c|c|c|c|}
\hline Domain & Sub-domain & $\begin{array}{l}\text { Differences between EL-ASD and } \\
\text { EL-TD }\end{array}$ & Age of appearance & Main papers reporting results \\
\hline \multirow[t]{8}{*}{ Motor development } & \multirow[t]{2}{*}{ Motor control } & Inconclusive results (1 study): & & \\
\hline & & Motor control predictor of ASD & 18 months & Brian et al. [46] \\
\hline & \multirow[t]{2}{*}{ General motor behaviour } & Inconclusive results (1 study): & & \\
\hline & & $\begin{array}{l}\text { No significant between-group differ- } \\
\text { ence }\end{array}$ & - & Brian et al. [46] \\
\hline & Gross motor development & Significant between-group difference & 14 months & $\begin{array}{l}\text { Landa et al. [41], Landa et al. } \\
\text { [47] }\end{array}$ \\
\hline & Fine motor development & Significant between-group difference & $\begin{array}{l}\text { From } 12 \text { months } \\
\text { on }\end{array}$ & $\begin{array}{l}\text { Landa et al. [41], Landa et al. } \\
\text { [47], Choi et al. [48] }\end{array}$ \\
\hline & \multirow[t]{2}{*}{ Posture } & Inconclusive results (1 study): & & \\
\hline & & $\begin{array}{l}\text { No significant between-group differ- } \\
\text { ence }\end{array}$ & - & Nickel et al. [27] \\
\hline \multirow[t]{7}{*}{$\begin{array}{l}\text { Repetitive/stereotyped } \\
\text { behaviour }\end{array}$} & $\begin{array}{l}\text { Repetitive/restricted } \\
\text { behaviour }\end{array}$ & Significant between-group difference & 18 months & $\begin{array}{l}\text { Sacrey et al. [49], Chawarska } \\
\text { et al. [50] }\end{array}$ \\
\hline & \multirow[t]{3}{*}{ Repetitive body movement } & Inconclusive results: & & \\
\hline & & $\begin{array}{l}\text { Significant between-group difference } \\
\text { versus }\end{array}$ & 12 months & Elison et al. [51] \\
\hline & & $\begin{array}{l}\text { No significant between-group differ- } \\
\text { ence }\end{array}$ & - & Damiano et al. [52] \\
\hline & Repetitive use of objects & $\begin{array}{l}\text { No significant between-group differ- } \\
\text { ence }\end{array}$ & - & $\begin{array}{l}\text { Elison et al. [51], Damiano } \\
\text { et al. [52] }\end{array}$ \\
\hline & \multirow[t]{2}{*}{ Repetitive interests } & Inconclusive results (1 study): & & \\
\hline & & Significant between-group difference & $6-12$ months & Brian et al. [46] \\
\hline \multirow[t]{5}{*}{ Sensory Processing } & \multirow{3}{*}{$\begin{array}{l}\text { Sensory behaviour and } \\
\text { interests }\end{array}$} & Inconclusive results: & & \\
\hline & & $\begin{array}{l}\text { No significant between-group differ- } \\
\text { ence versus }\end{array}$ & - & Brian et al. [46] \\
\hline & & $\begin{array}{l}\text { Sensory-oriented behaviour predictor } \\
\text { of ASD }\end{array}$ & 12 months & Zwaigenbaum et al. [33] \\
\hline & \multirow[t]{2}{*}{$\begin{array}{l}\text { Responses to sensory } \\
\text { stimuli }\end{array}$} & $\begin{array}{l}\text { Significant between-group difference } \\
\text { (tactile domain) }\end{array}$ & $\begin{array}{l}\text { From } 6 \text { or } \\
12 \text { months on }\end{array}$ & $\begin{array}{l}\text { Sacrey et al. [19], Wolff et al. } \\
\text { [53] }\end{array}$ \\
\hline & & $\begin{array}{l}\text { Significant between-group difference } \\
\text { (auditory domain) }\end{array}$ & 24 months & $\begin{array}{l}\text { Germani et al. [44], Wolff } \\
\text { et al. [53] }\end{array}$ \\
\hline \multirow[t]{8}{*}{ Play } & \multirow[t]{2}{*}{ General play behaviour } & Inconclusive results (1 study): & & \\
\hline & & Significant between-group difference & 9 months & Sacrey et al. [19] \\
\hline & \multirow[t]{2}{*}{ Functional play } & Inconclusive results ( 1 study): & & \\
\hline & & $\begin{array}{l}\text { No significant between-group differ- } \\
\text { ence }\end{array}$ & - & Christensen et al. [54] \\
\hline & \multirow[t]{2}{*}{ Non-functional play } & Inconclusive results (1 study): & & \\
\hline & & $\begin{array}{l}\text { No significant between-group differ- } \\
\text { ence }\end{array}$ & - & Christensen et al. [54] \\
\hline & \multirow[t]{2}{*}{ Symbolic play } & Inconclusive results (1 study): & & \\
\hline & & $\begin{array}{l}\text { No significant between-group differ- } \\
\text { ence }\end{array}$ & - & Christensen et al. [54] \\
\hline \multirow[t]{6}{*}{ Temperament } & \multirow[t]{2}{*}{ Reactivity } & Inconclusive results (1 study): & & \\
\hline & & Significant between-group difference & 18 months & Brian et al. [46] \\
\hline & \multirow[t]{2}{*}{ Transition } & Inconclusive results (1 study): & & \\
\hline & & Significant between-group difference & 18 months & Brian et al. [46] \\
\hline & \multirow[t]{2}{*}{ Surgency } & Inconclusive results (1 study): & & \\
\hline & & Significant between-group difference & From 8 months on & Pijl et al. [35] \\
\hline
\end{tabular}


Table 1 (continued)

\begin{tabular}{|c|c|c|c|c|}
\hline Domain & Sub-domain & $\begin{array}{l}\text { Differences between EL-ASD and } \\
\text { EL-TD }\end{array}$ & Age of appearance & Main papers reporting results \\
\hline & Positive affect & Significant between-group difference & 12 months & $\begin{array}{l}\text { Zwaigenbaum et al. [33], } \\
\text { Garon et al. [55] }\end{array}$ \\
\hline & \multirow[t]{3}{*}{ Approach } & Inconclusive results: & & \\
\hline & & $\begin{array}{l}\text { Significant between-group difference } \\
\text { versus }\end{array}$ & $\begin{array}{l}6 \text { months or } \\
24 \text { months }\end{array}$ & $\begin{array}{l}\text { Zwaigenbaum et al. [33], } \\
\text { Brian et al. [46], Garon } \\
\text { et al. [55] }\end{array}$ \\
\hline & & $\begin{array}{l}\text { No significant between-group differ- } \\
\text { ence }\end{array}$ & - & Del Rosario et al. [56] \\
\hline & \multirow[t]{3}{*}{ Activity } & Inconclusive results: & & \\
\hline & & $\begin{array}{l}\text { Significant between-group difference } \\
\text { versus }\end{array}$ & 6 months & Brian et al. [46] \\
\hline & & $\begin{array}{l}\text { No significant between-group differ- } \\
\text { ence from } 18 \text { months }\end{array}$ & - & del Rosario et al. [56] \\
\hline & \multirow[t]{2}{*}{ Adaptability } & Inconclusive results (1 study): & & \\
\hline & & Significant between-group difference & From 6 months on & Brian et al. [46] \\
\hline & Effortful control & Significant between-group difference & $\begin{array}{l}\text { From } 14 \text { or } \\
24 \text { months on }\end{array}$ & $\begin{array}{l}\text { Zwaigenbaum et al. [33], Pijl } \\
\text { et al. [35], Garon et al. [57] }\end{array}$ \\
\hline & \multirow[t]{2}{*}{ Emotion regulation } & Inconclusive results (1 study): & & \\
\hline & & $\begin{array}{l}\text { No significant between-group differ- } \\
\text { ence }\end{array}$ & - & Garon et al. [57] \\
\hline
\end{tabular}

EL group. In particular, at 12 months [32] or at 14 months [59] EL-ASD required more time to disengage from a stimulus than EL-TD, EL-Other and TL during the overlap condition. Additionally, saccadic reaction times at 12-13 months predicted social-communicative impairments at 24 months [33], ASD outcome [31] or the severity of autistic symptoms [32], measured by the ADOS at 36 months.

Finally, different developmental courses were found: TL and EL-TD but not EL-ASD showed decreased RT over time (range 6-36 months) in the overlap condition [32, 59]. Similar results were found during play situations. Attention disengagement, measured through the AOSI [65] at 12 months, predicted ASD at 24 months, according to Zwaigenbaum et al. [33]. Sacrey et al. [62] reported that EL-ASD did not disengage from the target after it was grasped, as compared to EL-TD and TL, although this pattern was evident from 12 until 24 months, no longer at 36 months.

\section{Attention shift and engagement $(n=4)$}

Sacrey et al. [62] and Gammer et al. [29] explored attention engagement during various play situations, as part of the AOSI [65] and ADOS [66]. In this context, they referred to engagement as the time period between the first eye movement towards the toy and the first hand movement towards that particular toy. Neither Sacrey et al. [62] nor Gammer et al. [29] found significant between-group differences in looking time towards the target before hand movement.
Additionally, although EL-ASD were less likely than EL-TD and TL to look away from the target before the grasp was complete, these eye movements accounted for a small minority of all visual engagements while the majority of visual engagements toward the target were appropriate [62].

Explored using the gap condition from the visual orienting task [33] and a play situation from the AOSI [65], attention shift (rather than engagement) was defined by two studies $[32,33]$ as the latency to gaze to the peripheral stimulus after a central stimulus has disappeared. In line with the two previous studies, Zwaigenbaum et al. [33] and Bryson et al. [32] did not find between-group nor within-group differences in attention shift at any age; consistently, attention shift did not predict the scores on the ADOS [62] at 24 [33] or 36 months [32].

\section{Visual tracking $(n=2)$}

Visual tracking was explored during the administration of the AOSI [65] in which it is defined as the ability to visually follow a moving object laterally across the midline. Gammer et al. [29] found that at 7 months but not at 14 months EL-TD showed higher scores in the visual tracking behaviour as compared to TL, although the authors did not report whether the scores indicate partial or full inability to track objects laterally. Conversely, EL-ASD and EL-TD did not significantly differ at any time point. Differently, Zwaigenbaum et al. [33] 


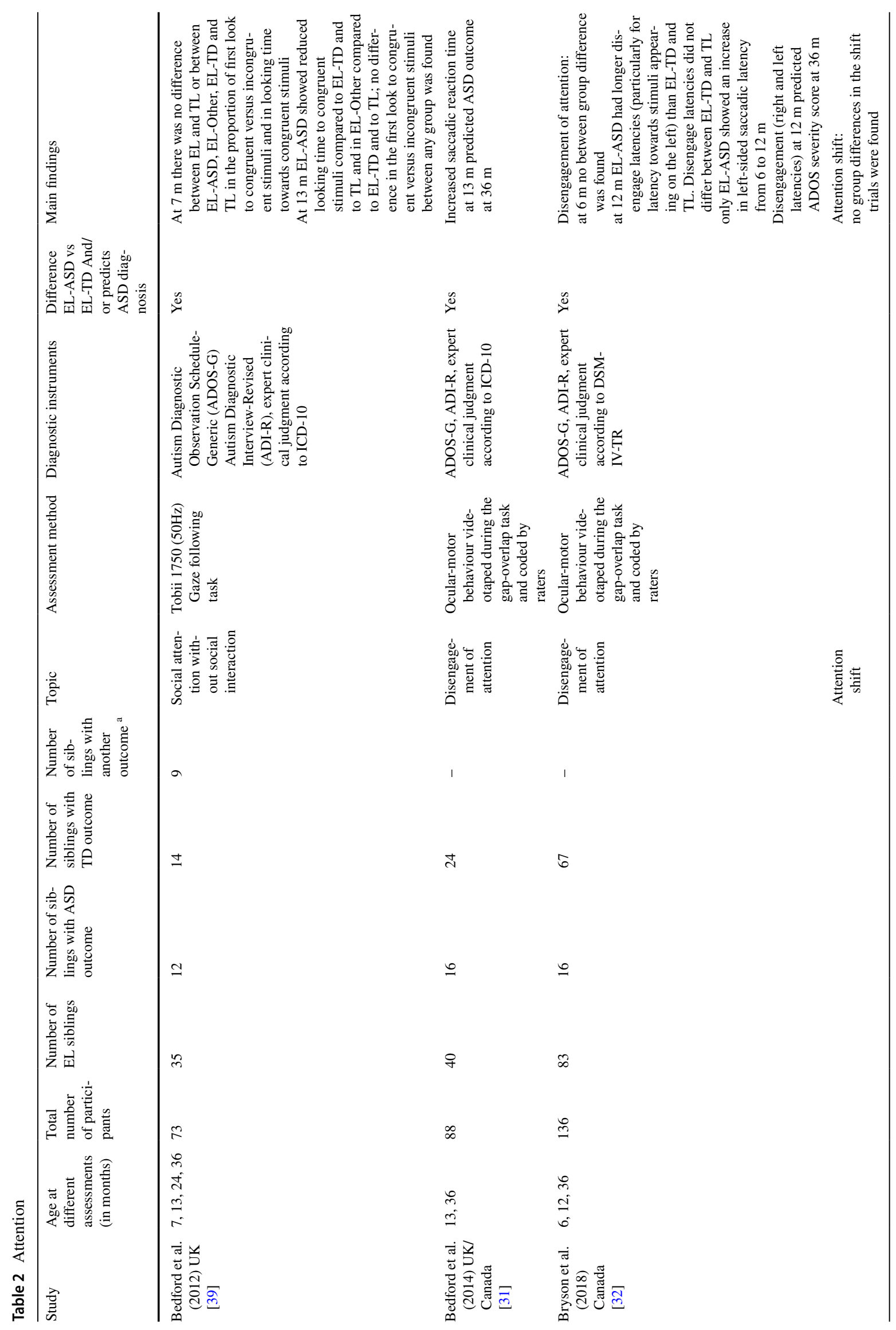




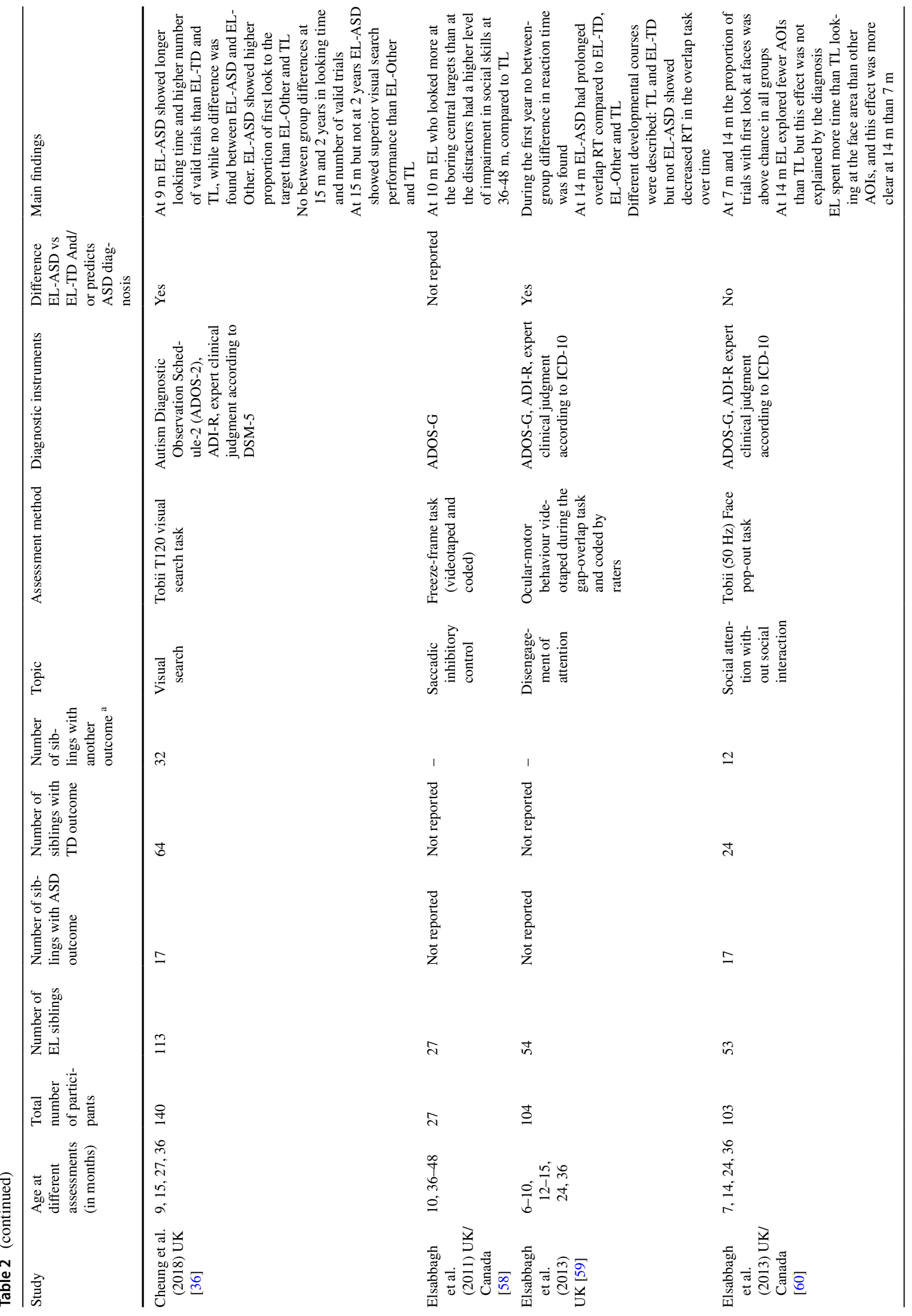




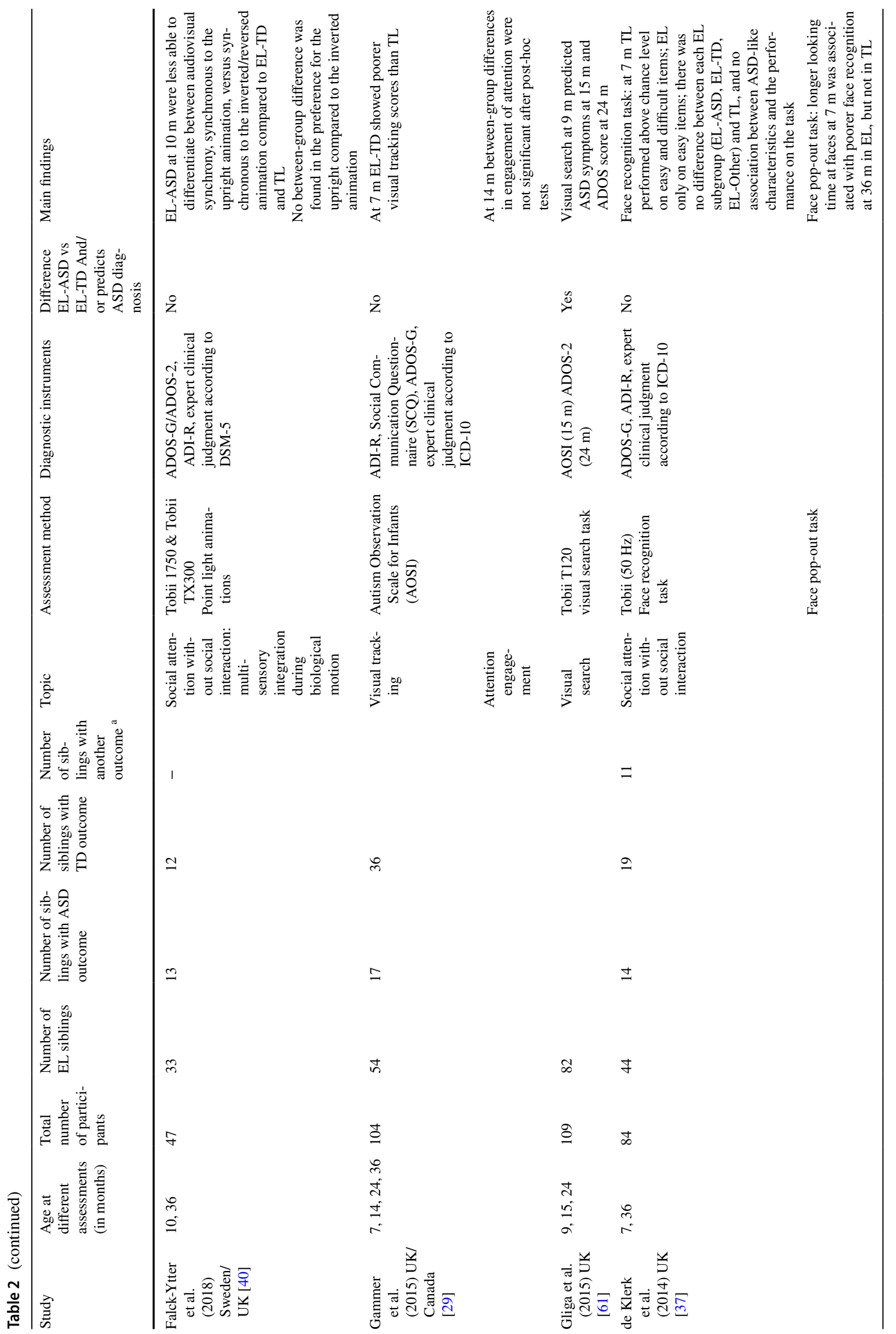




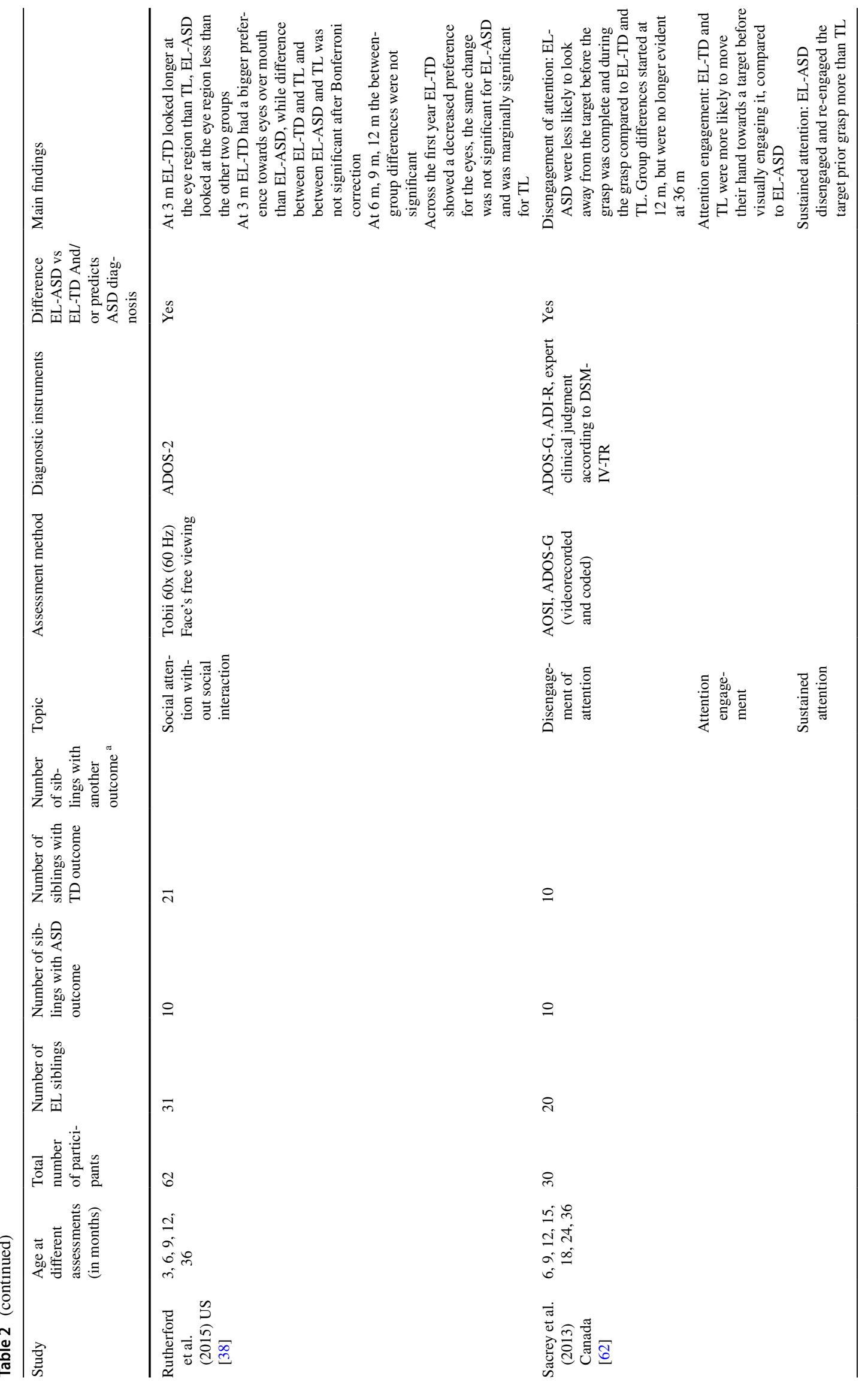




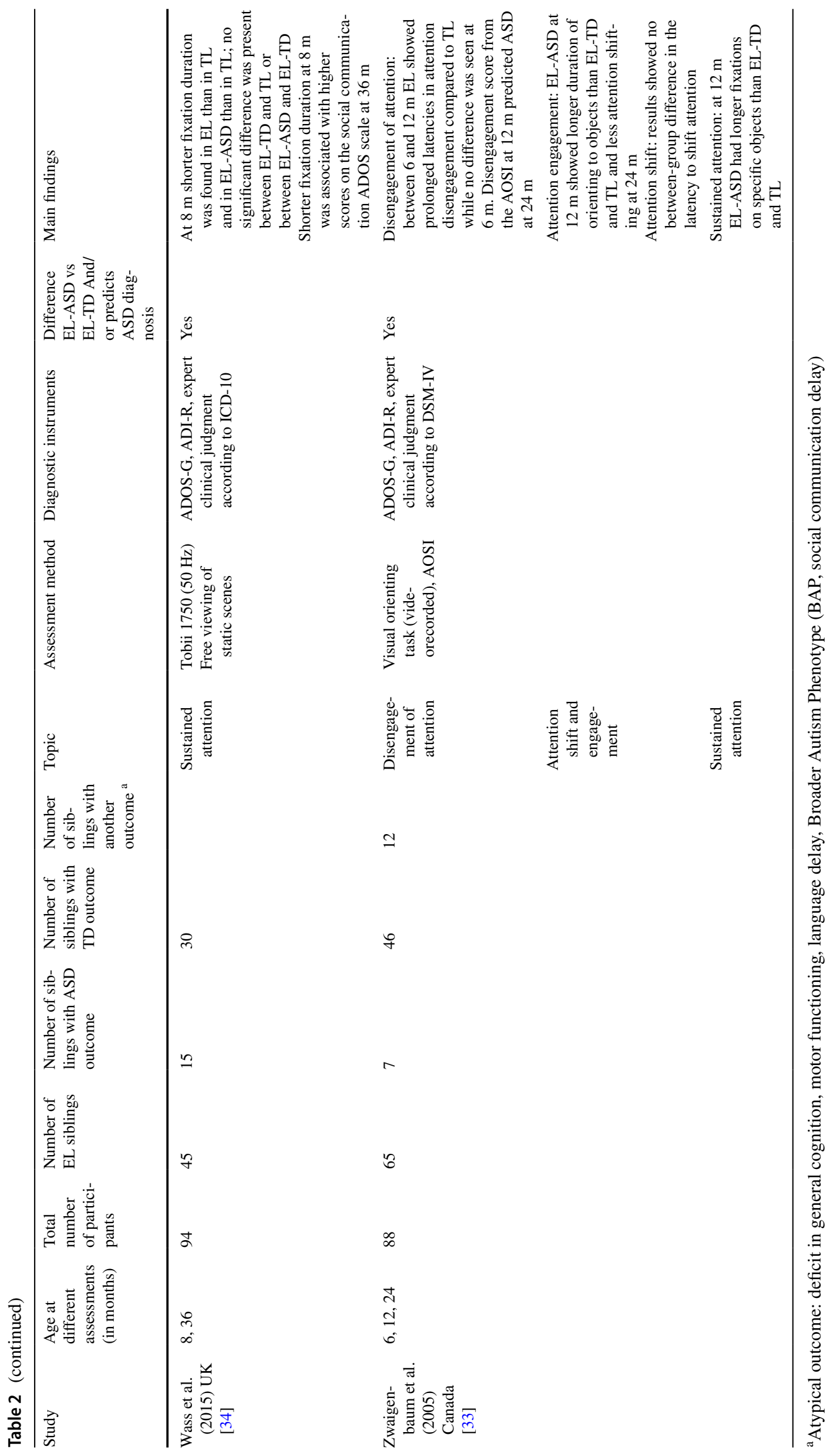


found that visual tracking at 12 months but not at 6 months predicted the ADOS score at 24 months.

\section{Sustained attention $(n=3)$}

Sustained attention was measured during a play situation as part of the AOSI and ADOS [62], during the exploration of static scenes [34] and through the Infant Behavior Questionnaire (IBQ; [67]), a parent report about children's exploration strategies in daily life [33]. Sacrey et al. [62] defined sustained attention as the continual visual engagement of the target from movement onset until the target has been grasped. Wass et al. [34] and Zwaigenbaum et al. [33] focused on the duration of fixations towards a stimulus, during a free play condition and through parent reports.

Results disclosed different patterns. Zwaigenbaum et al. [33] found that parents of EL-ASD described their children at 12 months with a tendency to fixate more on particular objects in the environment at the expense of a more active visual exploration, compared to parents of EL-TD and TL. Sacrey et al. [62] found that EL-ASD disengaged and engaged the target several times before grasping it, compared to EL-TD and TL, although the group by age interaction was no longer significant after post-hoc analyses. Wass et al. [34] found shorter fixation duration at 8 months in EL-ASD compared to TL, while EL-TD did not significantly differ from EL-ASD or TL.

\section{Saccadic inhibitory control $(n=1)$}

Defined as the combination of attentional flexibility and regulation of looking behaviour in response to changes in visual environment, saccadic inhibitory control was assessed in one study [58] using the Freeze-frame Task [68]. Children's task was to inhibit looking to peripherally presented distractors so as to keep a central stimulus animated. The authors measured the proportion of looks at distractors in boring and interesting trials and found that EL who looked more at central boring targets than at distractors at 10 months exhibited higher levels of impairment in social skills from 36 to 48 months compared to TL. No comparison within the EL group according to the diagnostic outcome was made.

\section{Visual search $(n=2)$}

A visual search task, comprised of an array of coloured distractor-letters and one target-letter, disposed on an imaginary circle, was presented to EL and TL while their ocular-motor behaviour was recorded, in two studies [36, 61]. Gliga et al. [61] and Cheung et al. [36] operationalized visual search accuracy as the proportion of trials in which the participant made a first look toward the target. Both studies showed enhanced visual search performance in EL-ASD but while in
Gliga et al. [61] visual search accuracy at 9 months predicted ASD symptoms already at 15 months and again at 2 years, Cheung et al. [36] concluded that between-group differences were no longer found at 2 years.

\section{Social attention without social interaction $(n=5)$}

Overall, three components of social attention were explored: face processing, gaze following behaviour, orienting to biological motion. Face processing was conceived as a combination of face recognition, scanning and face preference [37, 38, 60]. Elsabbagh et al. [60] and de Klerk et al. [37] explored face processing through the face pop-out task. In the task, sequences of five images (one face and four distractors) appeared on the screen while participants' eye movements were recorded. Distractors were cars, mobile phones, birds and face visual noise images from the same face presented in the sequence. The dependent variables were the proportion of trials with the first look at the face and the total amount of time spent looking at the face compared to the other areas of interest (AOIs). Results showed that EL looked at faces for a longer time than TL, and this pattern was clearer at 14 months than at 7 months. However, this finding was explained by the ASD diagnosis only in de Klerk et al. [37].

Rutherford et al. [38] explored face processing during the free viewing of various coloured dynamic videos each displaying a different face, several moments across development. They found that at 3 months EL-ASD showed the smallest preference for the eye region, followed by TL, who looked at the eye region less than EL-TD. Moreover, EL-TD showed a bigger preference for the eyes over the mouth than EL-ASD, while both EL-ASD versus TL and EL-TD versus TL did not differ after Bonferroni's correction. In addition, between-group differences were no longer apparent at 6,9 and 12 months. Finally, in EL-TD, and unlike EL-ASD, a decreased preference for eyes across the first year was found.

Gaze following behaviour was defined as the proportion of first looks to a congruent versus an incongruent object [39]. The visual stimuli consisted of two objects on a table and a female model looking down, then looking up (direct gaze) and then turning her head to look at one of the objects (shift). The object looked at by the model during shift was the congruent object and the non-gazed at object was the incongruent object. Bedford et al. [39] found that in the assessment at 13 months, but not at 7 months, EL-ASD looked at the congruent stimuli for less time than EL-TD and TL, while no difference was found between EL-ASD and EL-Other.

Lastly, perception of biological motion was conceptualized as an example of social information that is prioritized by typically developing infants and children [40]. Falck-Ytter 
et al. [40] assessed the effects of manipulation of audiovisual synchrony by presenting point light animations of diverse actions together with audio, with the same action being always shown in upright on one side of the screen and spatially inverted (and temporally reversed) on the other side. Sometimes the audio was coincidentally in synchrony with the inverted and reverse animation.

The authors found that EL-ASD oriented less to audiovisual synchrony expressed within biological motion, compared to EL-TD and TL. However, all groups showed a preference for the upright animation, suggesting that results are not due to differences in orienting to biological motion.

\section{Visual processing $(n=6$; Table 3$)$}

Visual processing was explored in three different manners: by the Visual Reception scale from the Mullen Scale of Early Learning (MSEL; [69]) in four studies [26, 41, 42, 47], in which a variety of abilities (i.e. visual discrimination, visual memory, visual organization, visual sequencing and visual-spatial awareness) were covered, by the overall looking behaviour during a free play situation, in one study [43], in which participants were presented with various objects of different size, shape, and texture, requiring different types of exploratory behaviours, and as one of the sensory domains of the parent questionnaire Infant Toddler Sensory Profile (ITSP; [70]), in one study [44].

Put together, results showed that abnormal visual processing at 6 months discriminated EL-Autism (referring to children with high ADOS scores, eligible for the diagnosis of Autism at 36 months) from EL-ASD, EL-TD and TL [41]. Differences were not disclosed before 14 [41] and 24 months [47] in EL-ASD compared to EL-TD and TL. Moreover, Landa et al. [41, 47] found a developmental trend characterised by a decrease in visual processing abilities between the first and the second birthday (and until 36 months-evaluation in Landa et al. [41]), although these findings came from the same research group. In contrast, Libertus et al. [42] did not find any difference at 6 months between EL-ASD and EL-TD but they did not include any other assessment between 6 and 36 months.

Kaur et al. [43] explored the overall looking behaviour towards a set of toys and found that EL showed excessive visual exploration irrespective of the novelty of the objects used compared to TL, at 6 months and 12 months while no difference was reported within the EL group. Germani et al. [44] conceptualized visual processing as one of the sensory processing subdomains and, in contrast with previously mentioned studies, did not find any significant difference at 24 months between EL-ASD, EL-TD and TL.

\section{Executive functioning ( $n=1$; Table 4$)$}

St John et al. [45] assessed children's executive functioning through the A-not-B task [71]. Participants needed to look as a toy was hidden to the right or left of the midline and were encouraged to find the toy after a few seconds delay. The side was reversed after the toy was found on two consecutive trials. Authors measured the proportion of total correct reaches by total trials, as an indicator of working memory (WM), and the proportion of total correct reaches on reversal trials by total reversals trials, which offers a measure of response inhibition.

Results showed an improvement in the WM and inhibition performance of TL between 12 and 24 months, compared to EL-ASD and EL-TD, who did not differ. No between-group differences in WM or response inhibition were found at 12 months. On the contrary, the WM and inhibition performance of EL-ASD and EL-TD at 24 months was significantly worse compared to TL, although no difference was found between the EL subgroups.

\section{Motor functioning ( $n=11$; Table 5$)$}

Three sub-domains were identified: motor control and general motor behaviour, fine and gross motor milestones and posture.

\section{Motor control and general motor behaviour $(n=1)$}

Motor control and general motor behaviour have been assessed by Brian et al. [46] during the administration of the AOSI [65]. In the AOSI motor control is defined as the degree in which motor behaviour is goal-directed, organised and modulated while general motor behaviour comprises atypical gait, locomotion, motor mannerism/postures or repetitive motor behaviour. The authors found that at 18 months motor behaviour was more atypical in EL-ASD compared to EL-TD and TL. Moreover, EL-ASD showed abnormal motor control compared to TL, while differences between EL-ASD and EL-TD were not significant after Bonferroni correction. Nonetheless, motor control at 18 months contributed to predict ASD at 36 months.

\section{Fine and gross motor milestones $(n=9)$}

Motor milestones were assessed using four different measures: the MSEL [69], the Peabody Developmental Motor Scales-2 (PMDS-2; [72]), recordings from the AOSI [65] and ADOS [66] and a free play situation. From the MSEL the Gross motor scale, that assesses central motor control and mobility, and the Fine motor scale, an indicator of visual-motor ability, were considered [26, 41, 42, 47, 48, 63]. LeBarton et al. [64] used the PMDS-2 [72] a standardized, 
experimenter-administered observational measure, comprised of the Stationary subscale to test gross motor skills and the Grasping and Visual-Motor Integration subscales to test fine motor skills. Sacrey et al. [49] analysed the recordings from the AOSI [65] and ADOS [66] and coded the reach-to-grasp measures (which included orient, lift, advance, pronation and grasp). Finally, Kaur et al. [43] used a less structured play situation, in which various objects of different size, shape and texture were presented one at a time and grasping, dropping and mouthing were coded.

The pattern of gross motor development was coherent in most of the studies showing no difference in the gross motor abilities at 6 months between EL-ASD and EL-TD [41, 42, 47, 64]. Differences between EL-ASD and EL-TD appeared at 14 months according to two studies [41, 47]. Coherently, gross motor abilities at 6 months could not predict ASD at 36 months [63]. Differently, Sacrey et al. [49] identified worse scores in reach-to-grasp movements, particularly in orient (head and eye movements to fixate the target prior reaching it) and pronate (hand pronates over the target and digits shape to target size) movements in EL-ASD than EL-TD and TL from 6 months, although no Group $\times$ Age interaction was found.

Uniquely, Estes et al. [26] followed up EL children with a later diagnosis of Autism Disorder (EL-Autism) and found that they had a lower score on the Gross motor scale already at 6 months.

Results for the fine motor domain based on the MSEL [69] and the PMDS-2 [72] revealed that at 6 months fine motor competencies predicted 36 months ASD diagnosis, as reported by Iverson et al. [63], discriminated EL and TL according to Libertus et al. [42] and LeBarton et al. [64] but not according to Choi et al. [48]. Differences within the EL group between EL-ASD and EL-TD appeared during the second year (from 12 months in Choi et al. [48], at 14 months in Landa et al. [41, 47]) while in Estes et al. [26] fine motor development at 24 months discriminated EL-Autism from EL-TD and EL-ASD only from TL. Moreover, the exploration of various subcomponents of fine motor development by Kaur et al. [43] during a play situation showed less grasping and dropping of a rigid ball, less mouthing of a rattle at 6 months, together with delayed dropping of objects between 12 and 15 months, in EL compared to TL. Conversely, Sacrey et al. [49] and LeBarton et al. [64] did not find significant between-group differences on grasping.

\section{Posture $(n=1)$}

Nickel et al. [27] explored the posture repertoire in EL and TL during everyday activities and semi-structured play, which were videotaped during several moments of development (between 6 and 14 months) and coded within the categories of lying, sitting, kneeling and standing. Betweengroup differences were found both in the variety of posture repertoire and in the stability over time of each posture. Between 6 and 12 months, EL-Autism were seen in half as many different postures as EL-TD and TL but this difference was no longer visible at 14 months. Moreover, at 6 months EL spent significantly more time in supported sitting and less time in unsupported sitting than TL. Finally, EL-Autism initiated new postures less frequently than EL-TD at 6,9 and 12 months. However, by 14 months frequencies of infantinitiated postures for EL-Autism infants were much closer to the EL group mean.

\section{Repetitive/stereotyped behaviour ( $n=5$; Table 6)}

This domain refers to repetitive and/or stereotyped behaviour, body movements, interests and use and manipulation of objects. Various assessment tools were chosen in different studies: ADOS [66], the Repetitive and Stereotyped Movement Scales (RSMS; [73]), from which object and body scores were derived, and a report of parents' concerns, developed by Sacrey et al. [19]. Parents of EL-ASD first noticed a peculiar pattern of repetitive-restricted behaviour (RRBs) at 9 months compared to parents of TL and at 18 months compared to parents of EL-TD [19]. Coherently, Chawarska et al. [50] found that repetitive behaviour at 18 months predicted an ASD diagnosis at 36 months. Elison et al. [51] found that repetitive use and manipulation of objects discriminated EL and TL at 12 months, while Damiano et al. [52] found higher rates of total RSMS in EL than TL at 12-24 months, but no interaction between group and RSM type. In both studies, EL-ASD and EL-TD did not significantly differ in the object cluster subscale. Repetitive body movements were explored in two studies: while Elison et al. [51] found a clear pattern of repetitive body movements in EL-ASD at 12 months compared to EL-TD and TL, Damiano et al. [52] found no clear difference between EL-ASD and EL-TD in the body movement repertoire. Finally, repetitive interests seem to better discriminate EL-ASD and EL-TD at an early stage (6-12 months) [46].

\section{Sensory processing $(n=5$; Table 7$)$}

Five studies explored the association between early differences in the sensory domain and later ASD diagnosis. Germani et al. [44] referred to the Infant Toddler Sensory Profile (ITSP; [70]), a parent-report measure of behavioural responses to sensory stimuli, across five sensory domains (auditory, visual, tactile, vestibular and oral) as well as of a child's reaction to sensory experiences. Brian et al. [46] and Zwaigenbaum et al. [33] focused on atypical sensory behaviours and interests (i.e. use of play materials in a selfstimulatory way) observed during the administration of the 


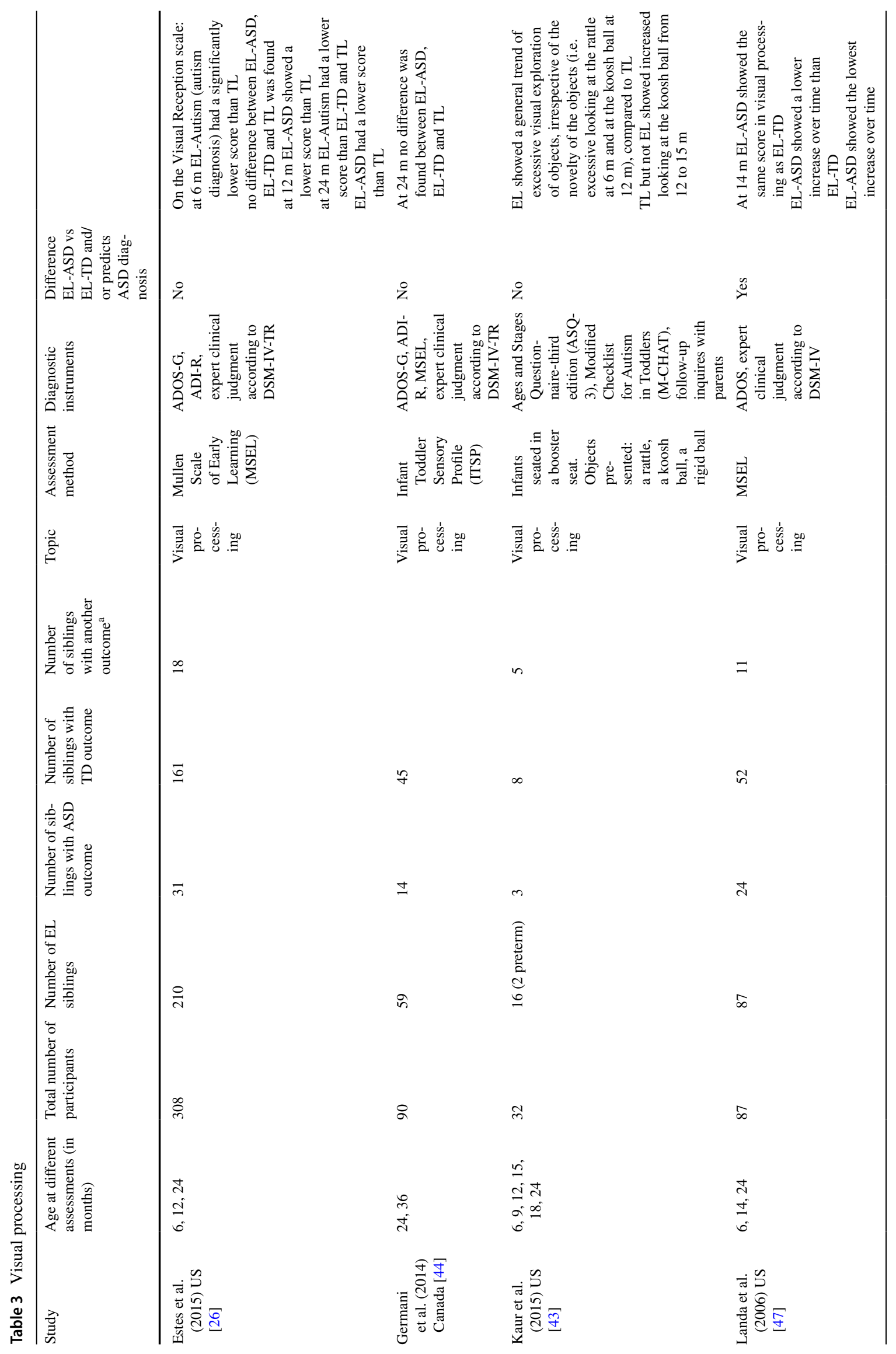




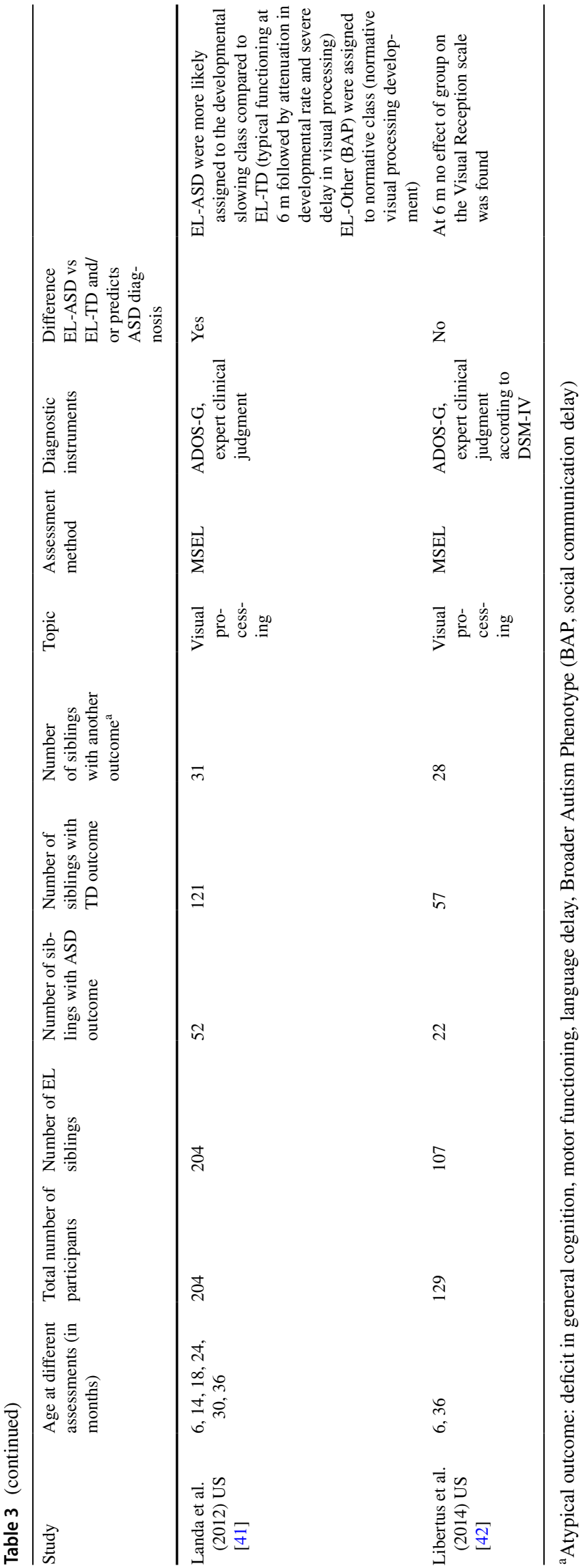

AOSI [65], Wolff et al. [53] used the Sensory Experiences Questionnaire (SEQ; [74]), a parent-report measure of behavioural responses to a range of common sensory stimuli and Sacrey et al. [19] based their assessment on reports of parent's sensory concerns from an interview that they had developed. Sacrey et al. [19] reported parents' first concerns in sounds, texture and visual inspection in EL-ASD by 6 months compared to parents of EL-TD and TL (who did not differ) while Wolff et al. [53] reported parents' concerns from 12 months, age at which parents of EL-ASD observed higher tactile and hyper-sensory responsivity, as compared to parents of EL-TD and TL, with differences increasing from 12 to 24 months in all sensory domains. Zwaigenbaum et al. [33] stated that the use of parts of the body or play materials in stereotyped, self-stimulatory ways (i.e. rubbing hands repeatedly over tables, dangling a string of beads and waving them in front of his/her eyes) at 12 months but not at 6 months predicted ASD at 24 months. Brian et al. [46] found that at 18 months both EL-ASD and EL-TD showed more atypical sensory behaviours (i.e. smelling of toys, staring at hands/shapes/objects, or feeling textures) compared to TL, while EL-ASD and EL-TD did not differ after Bonferroni's correction. Finally, conflicting results emerge at the 24 months assessment. Germani et al. [44] found that EL-ASD showed abnormalities in the auditory processing compared to EL-TD and TL while no difference was found in the visual, tactile, vestibular and oral domains. On the contrary, Wolff et al. [53] reported anomalies in all sensory subdomains.

\section{Play $(n=2 ;$ Table 8$)$}

Children's play behaviour was explored through a parent questionnaire, developed by the authors [19], to deepen general parent concerns about play as well as a free play situation videotaped and coded [54]. The free play assessment explored various aspects of play: functional play (i.e. the appropriate use of an object or the conventional association of two or more objects), symbolic play (i.e. the ability to pretend an object is present when it is not or to extend the function of an object to another object), repeated play (i.e. repeated behaviour, repetition of functional or symbolic actions, atypical actions).

Parents of EL-ASD reported their first concerns about play skills at 9 months compared to parents of EL-TD and TL, who did not differ, after post-hoc analyses [19]. Results of the free-play assessment showed that at 18 months ELASD had significantly fewer novel self-directed and otherdirected functional play behaviour (defined as the appropriate use of an object or the conventional association of two or more objects) than TL (although the differences in the selfdirected functional play disappeared after controlling for verbal mental age). Furthermore, both EL-ASD and EL-TD 


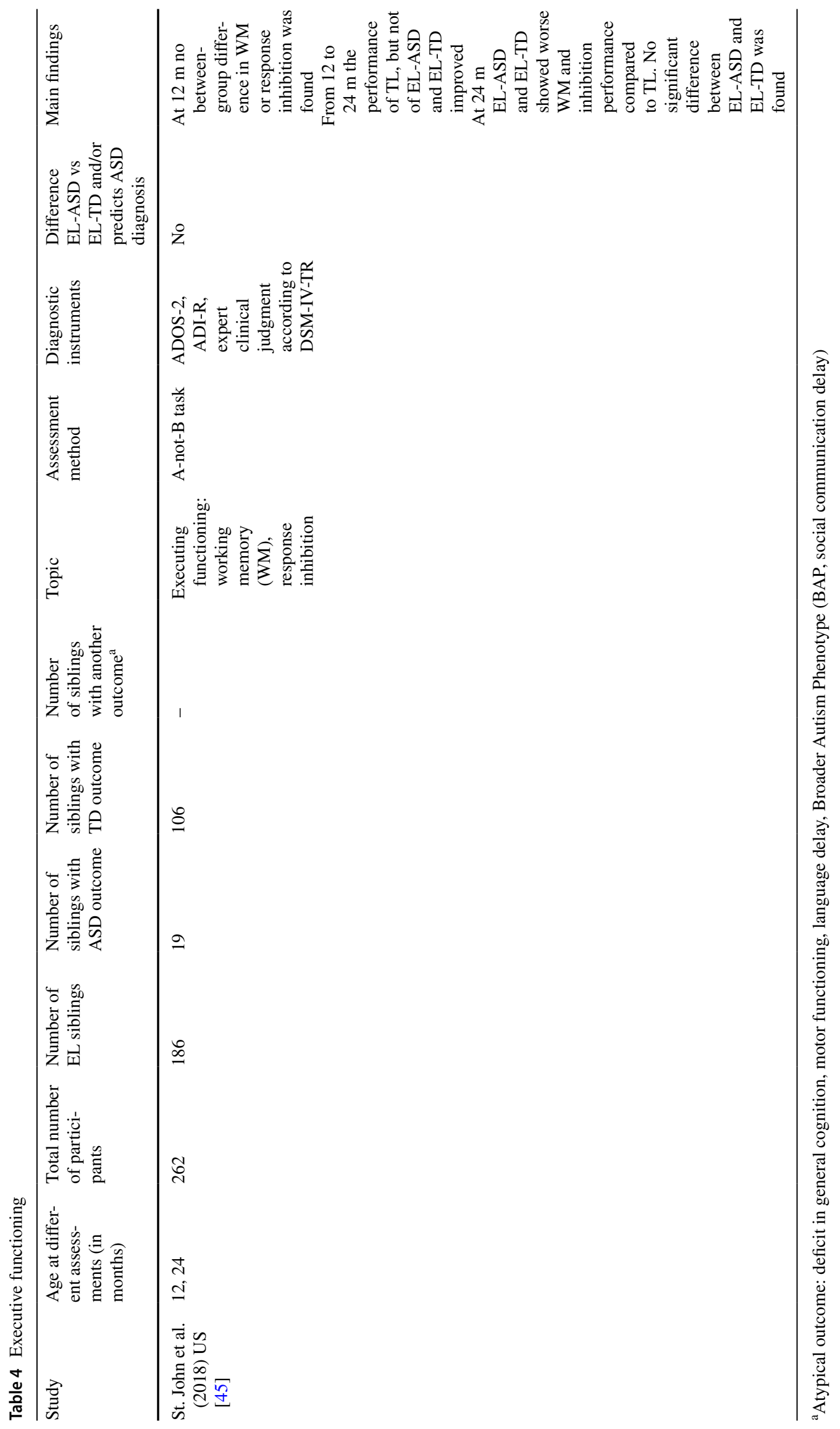




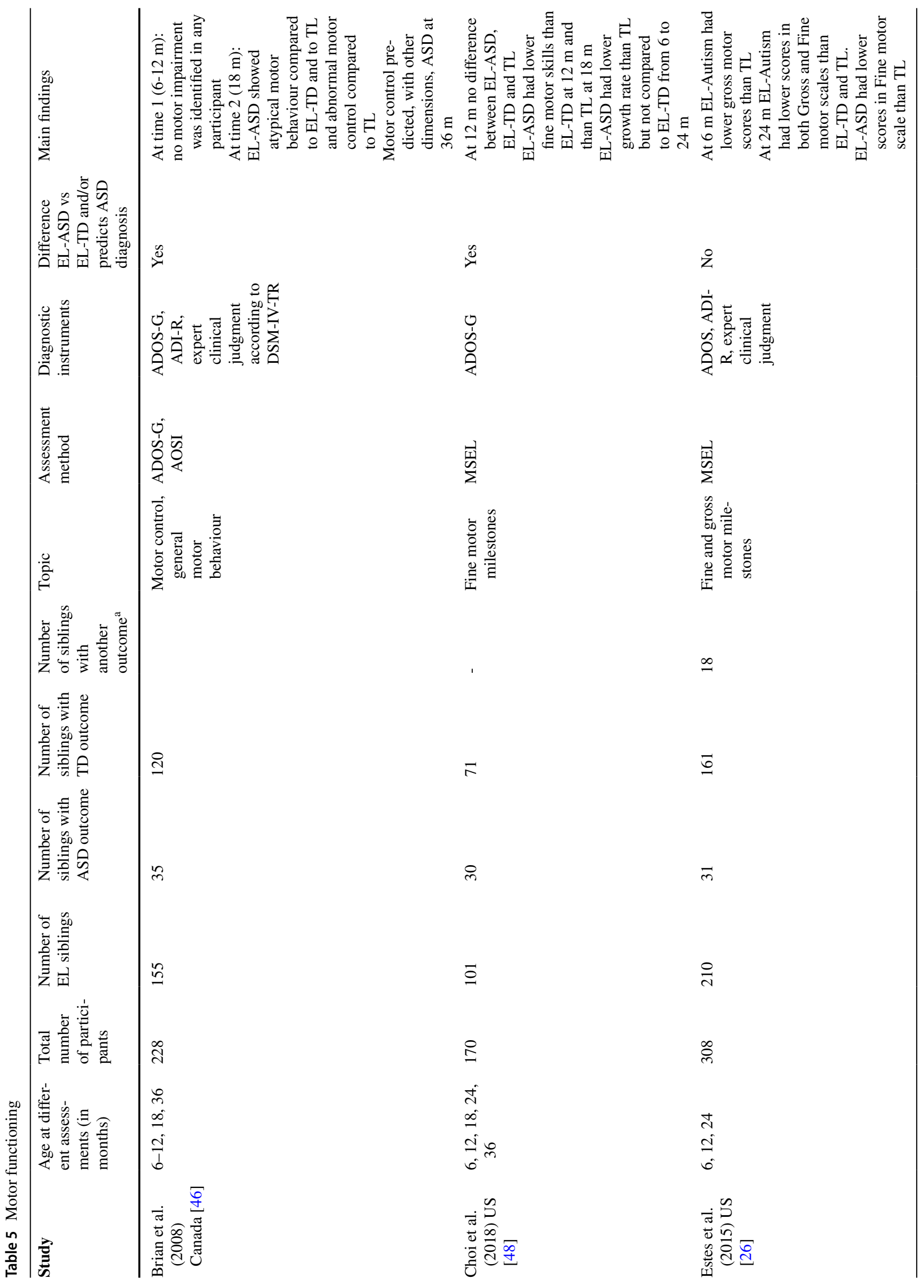




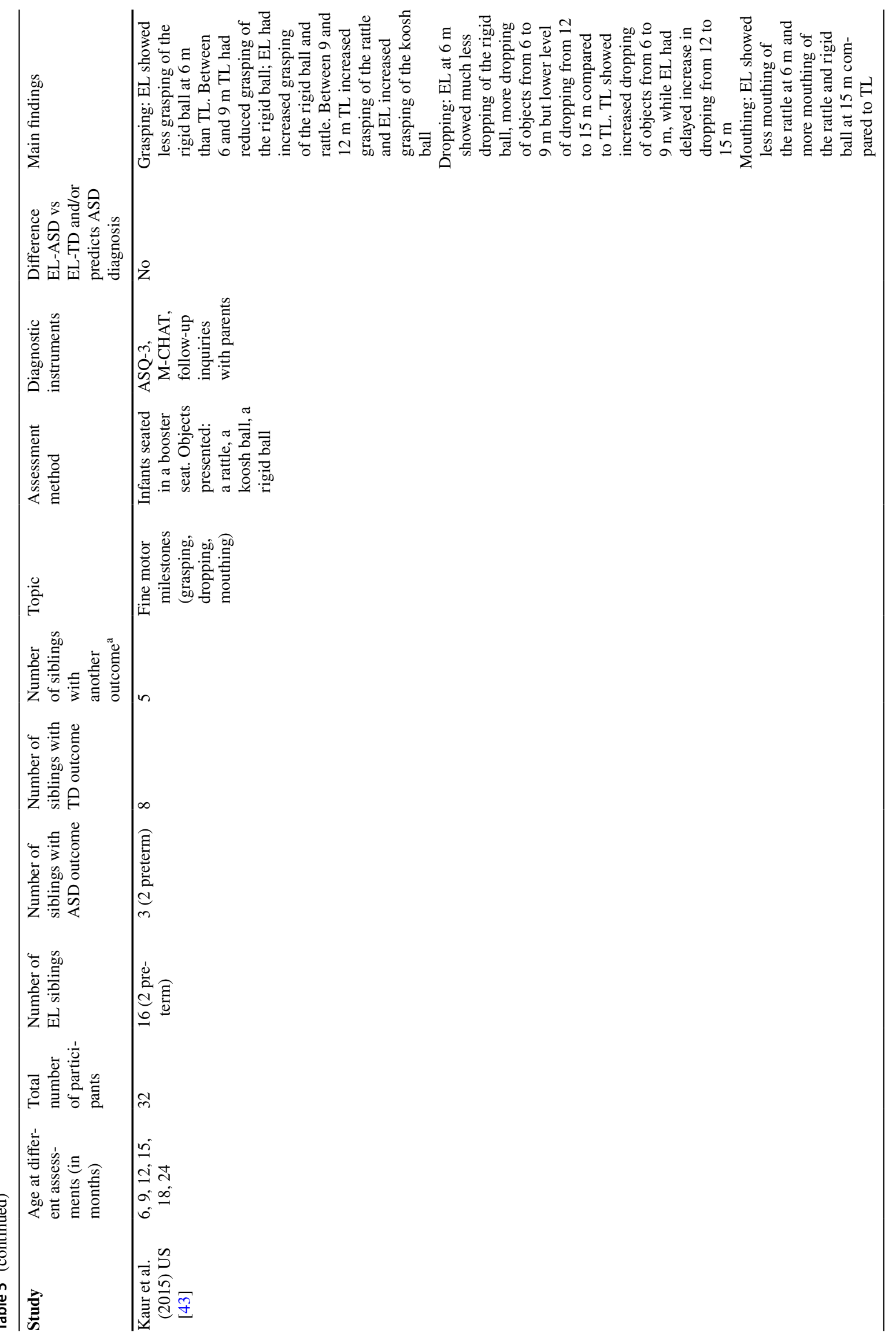




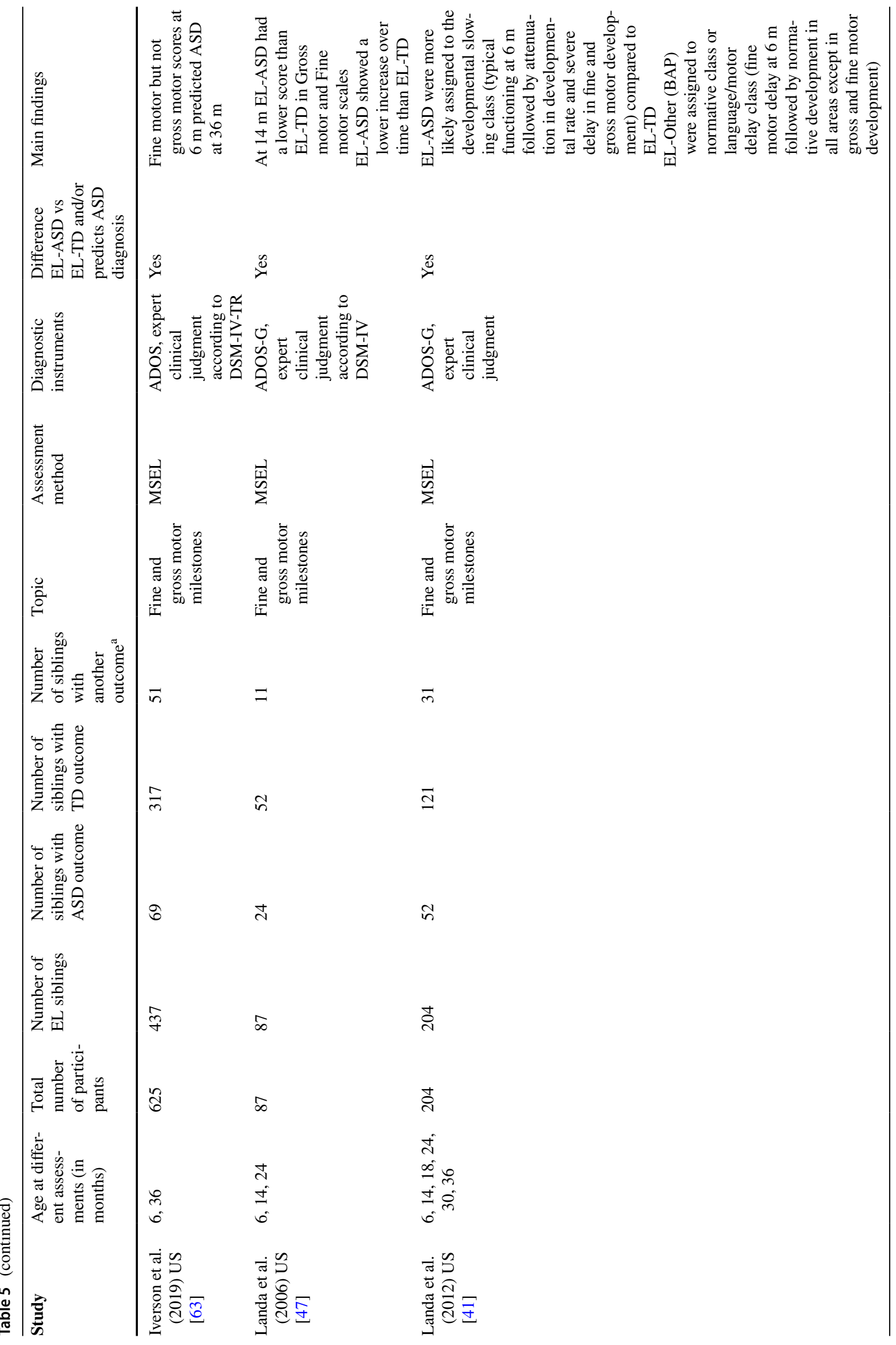




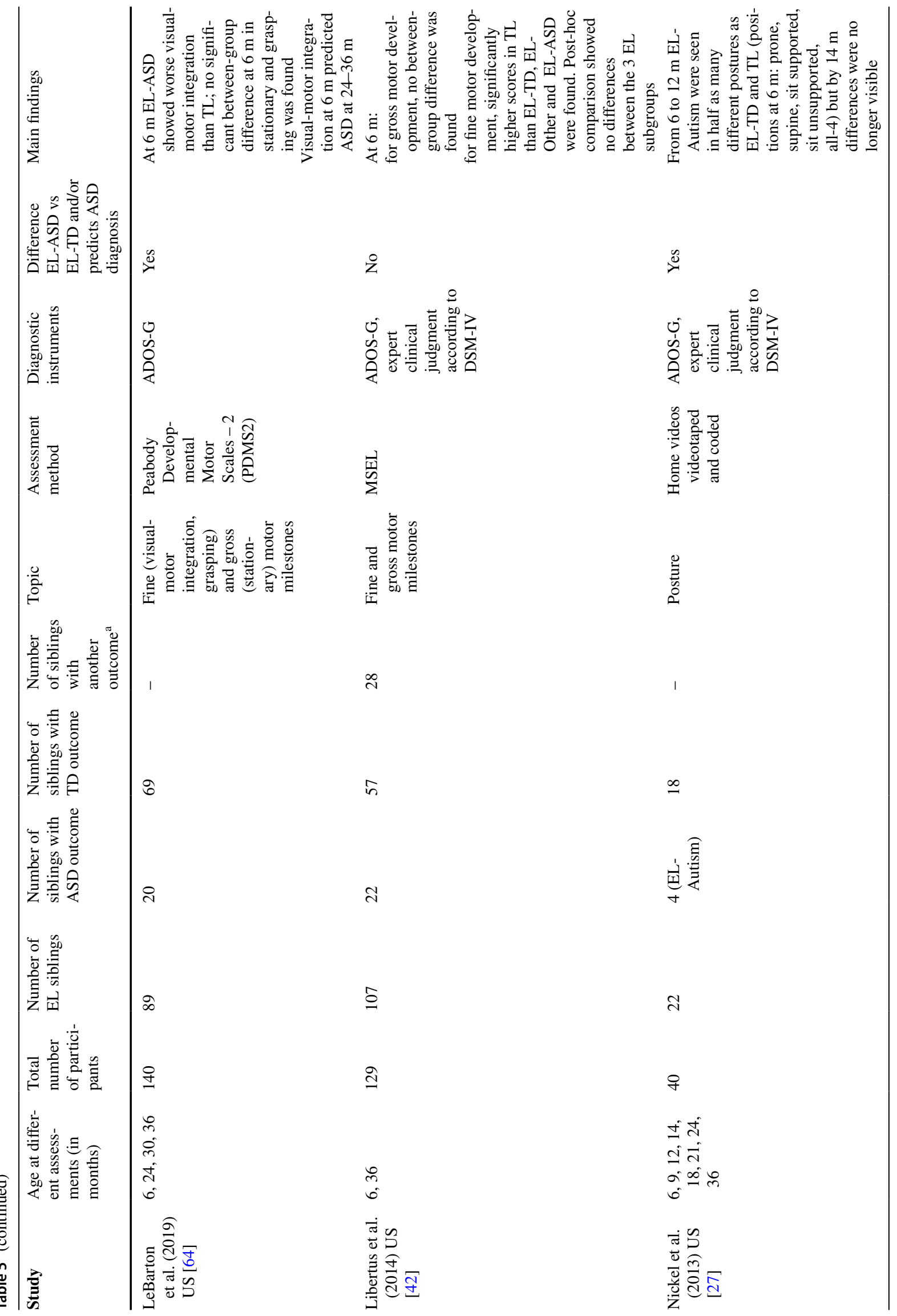


520

European Child \& Adolescent Psychiatry (2021) 30:497-538



Springer 
European Child \& Adolescent Psychiatry (2021) 30:497-538

521

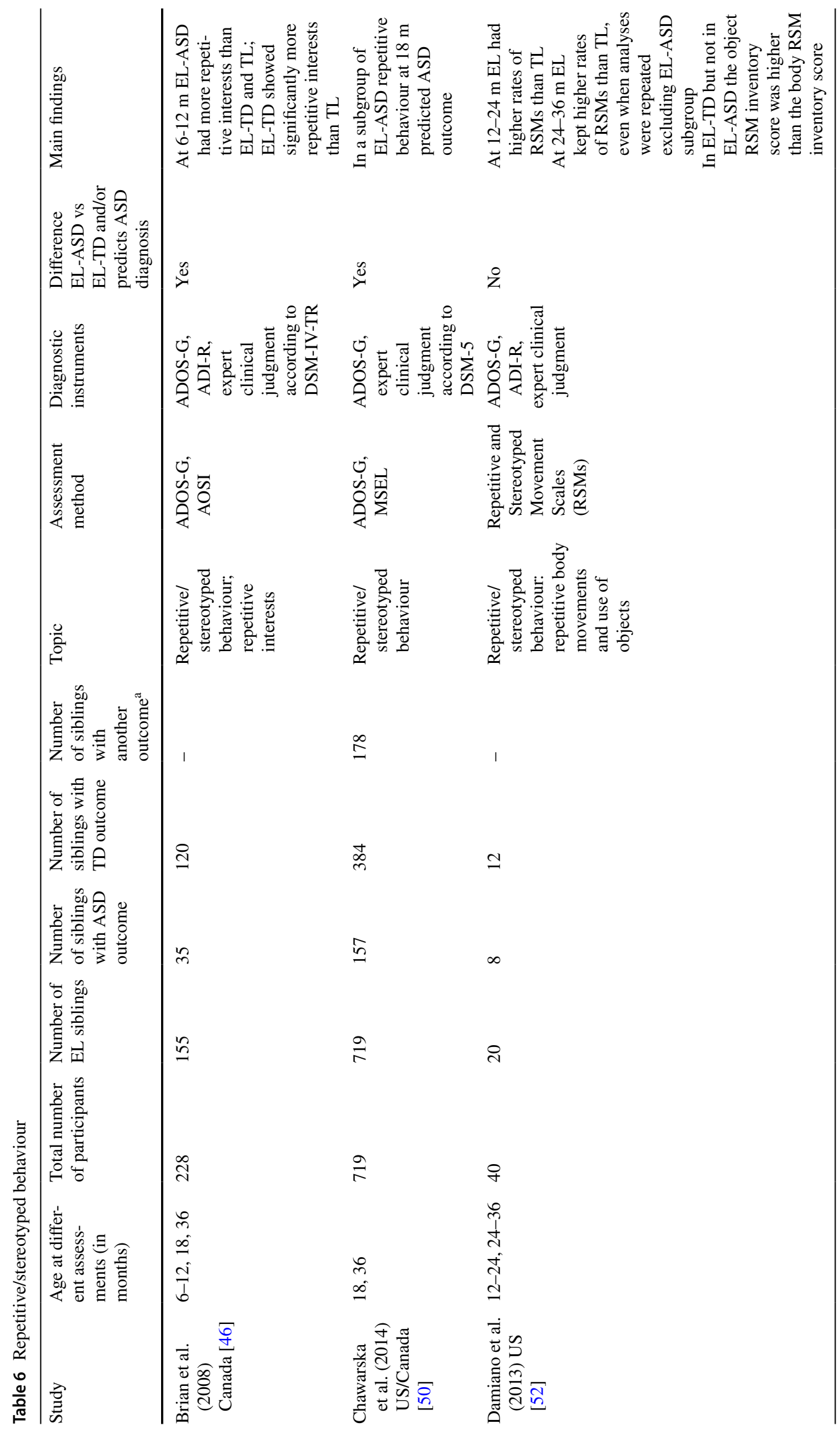

Springer 


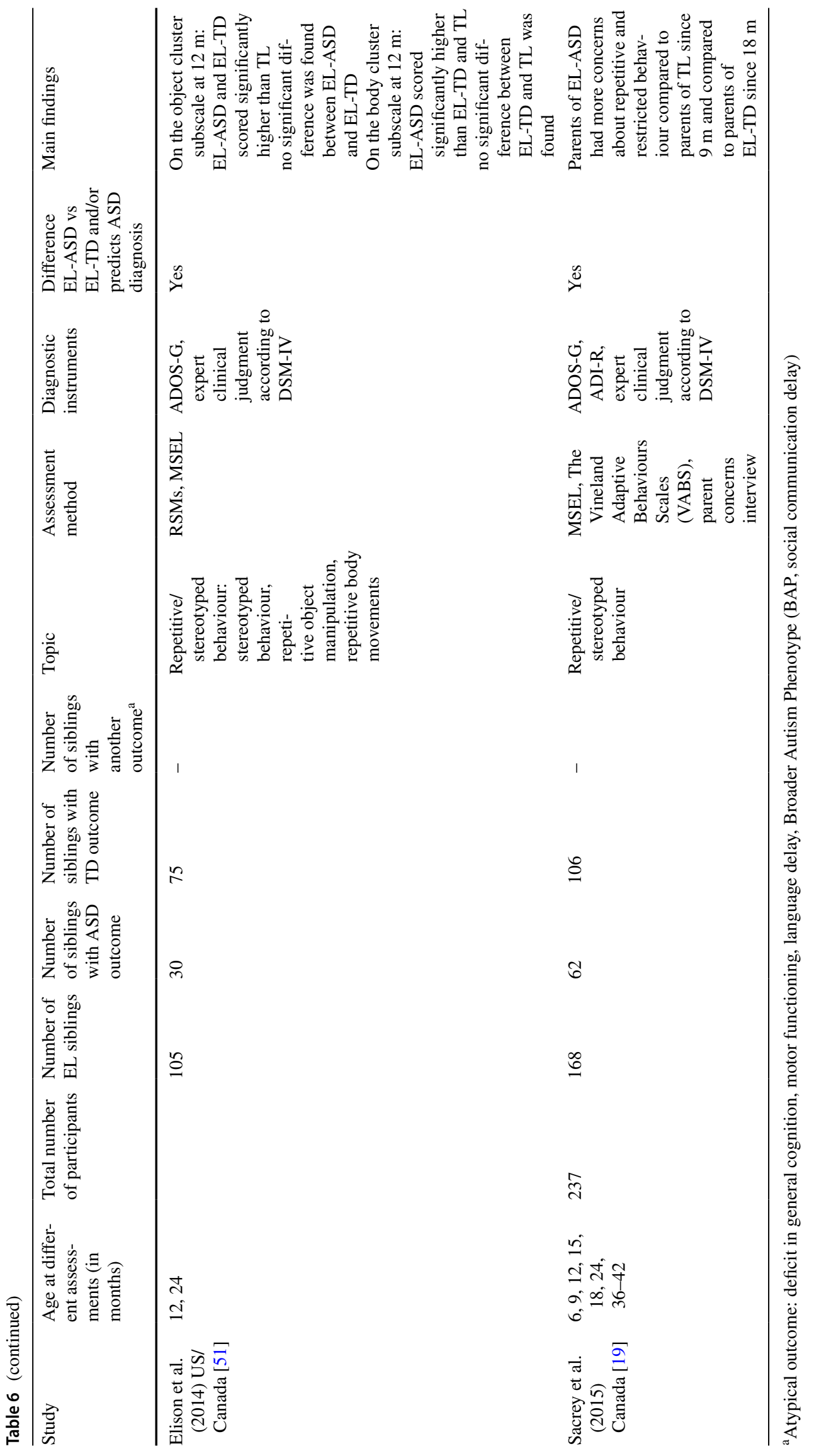




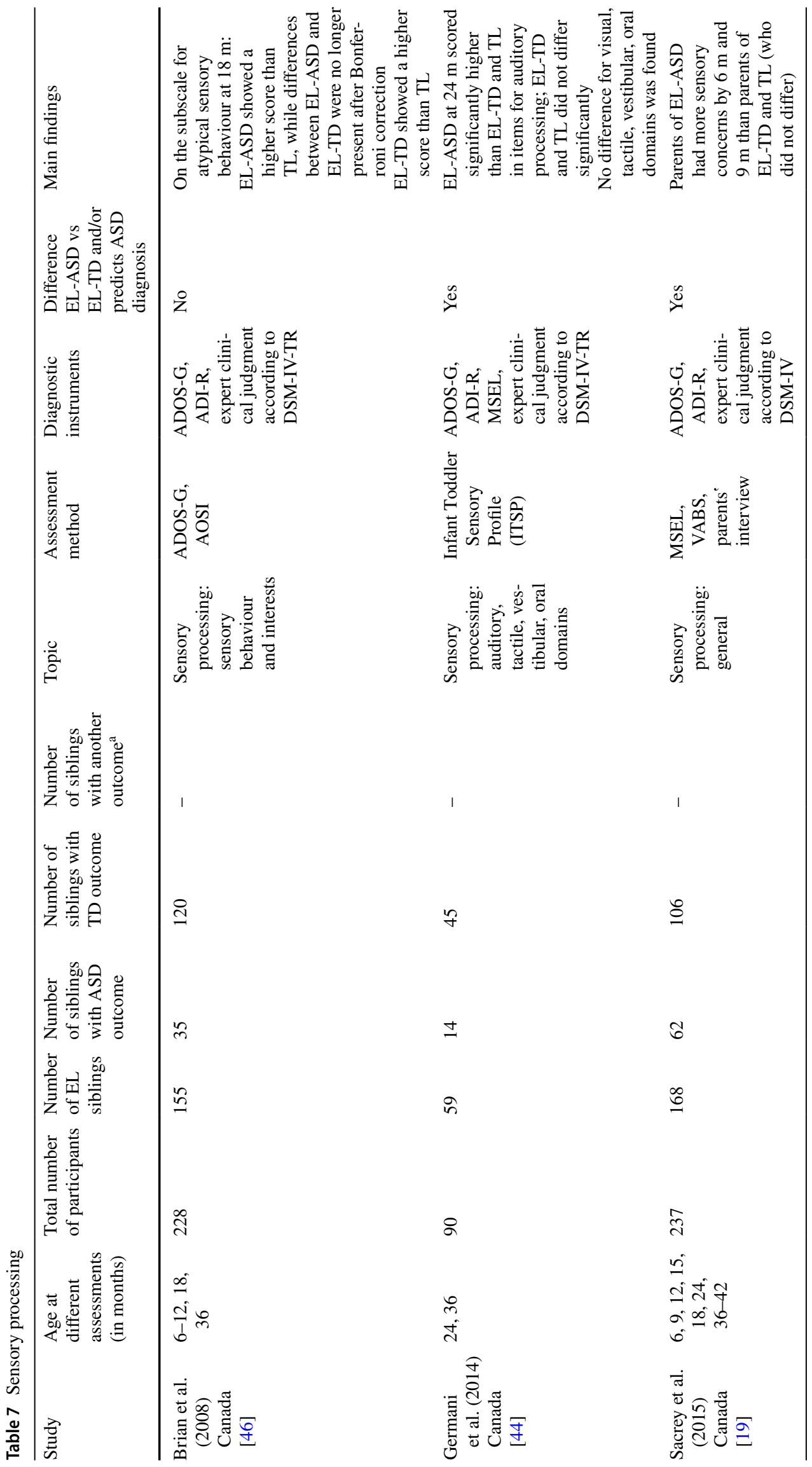









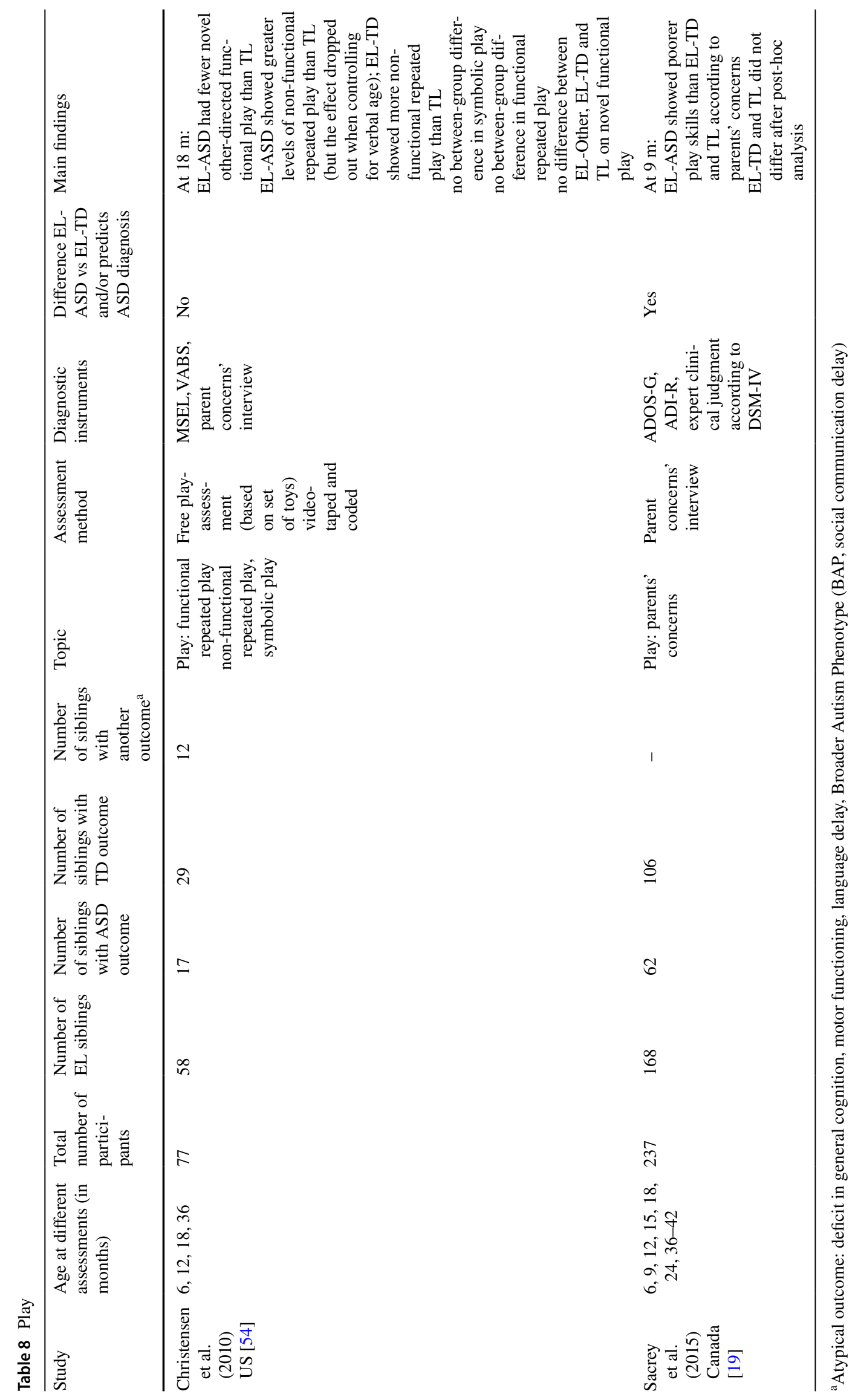









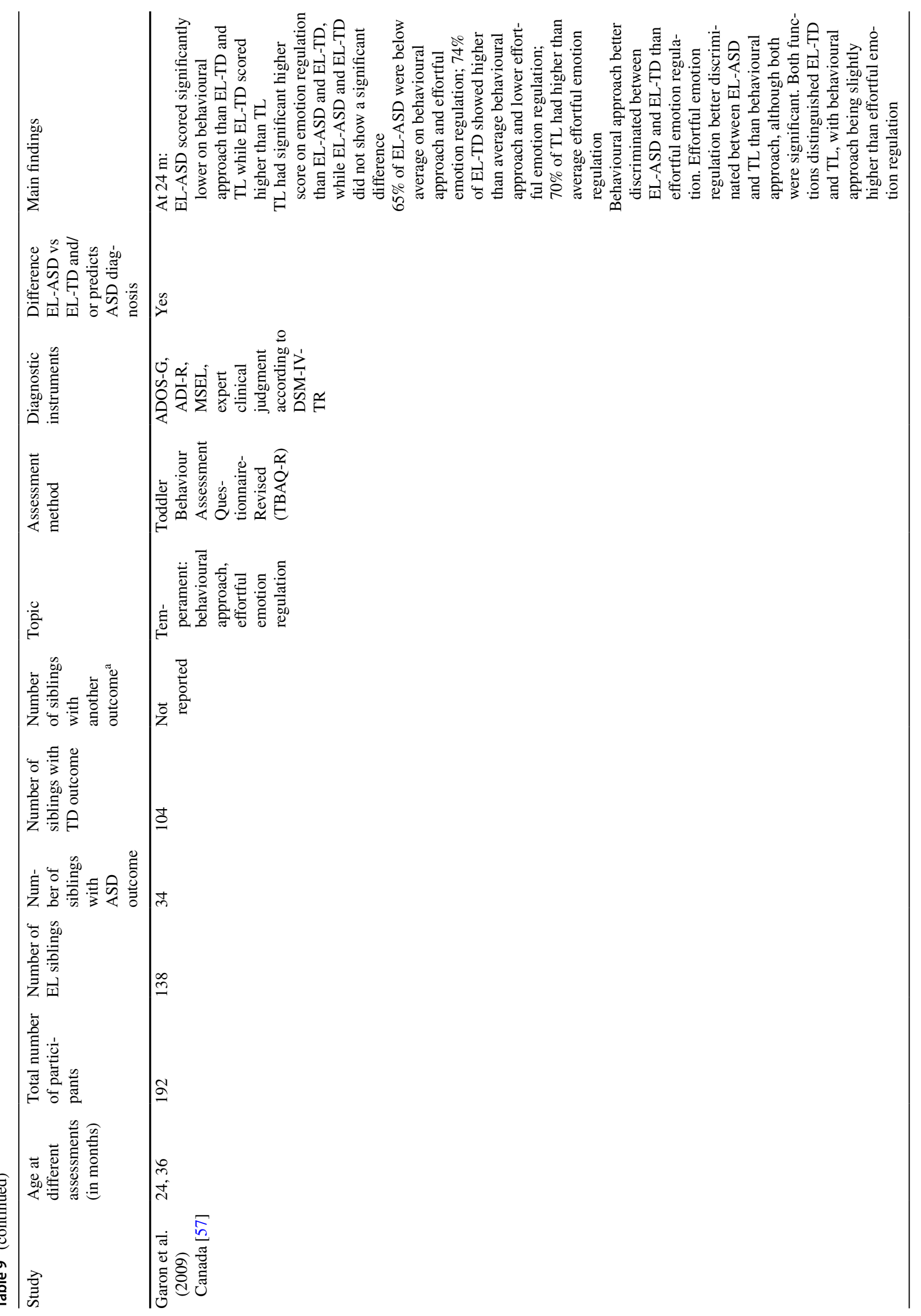




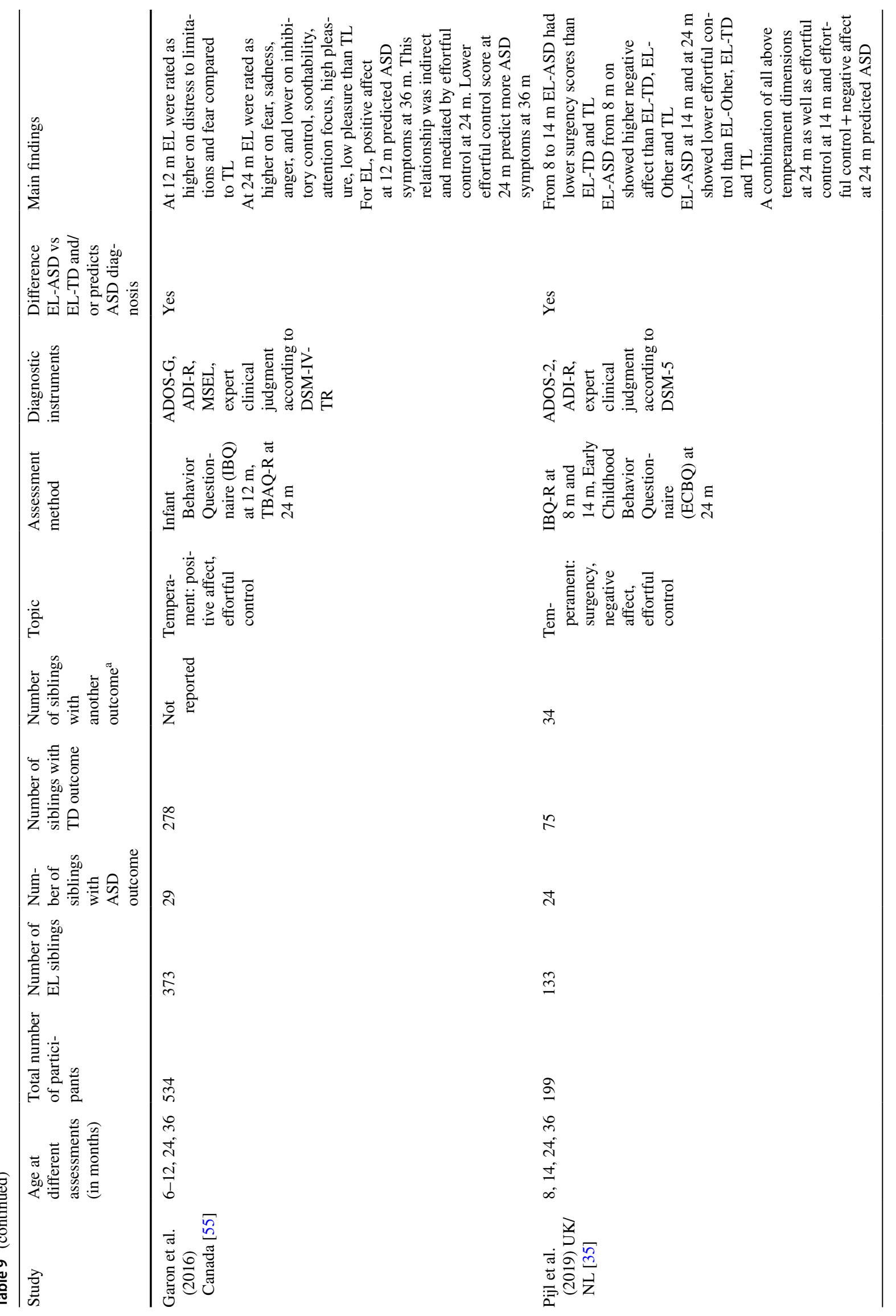




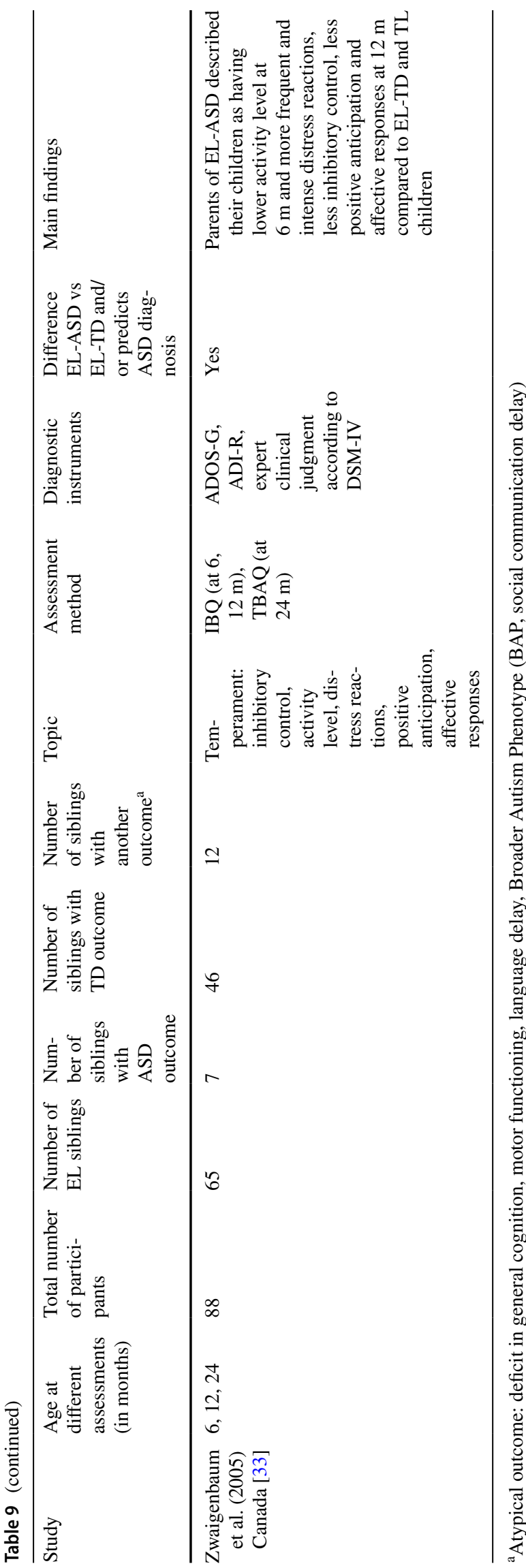

exhibited greater levels of non-functional repeated play than TL (although this effect dropped out when controlling for verbal age), while no significant difference was found within the EL group. On the contrary, EL-ASD and TL did not differ in functional repeated play and in symbolic play [54].

\section{Temperament ( $n=6$; Table 9)}

Several temperament dimensions have been explored in children at high risk for ASD. Results are based on the AOSI [65] in one study [46] and on the parent questionnaires Carey Temperament Scale (CTS; [75]), Toddler Behaviour Assessment Questionnaire (TBAQ; [76]), The Early Childhood Behaviour Questionnaire [77] and IBQ [67] in all others [33, 35, 55-57].

Brian et al. [46] assessed reactivity and transition from the AOSI [65]. Reactivity codes for the behavioural responses to objects and events and is expressed by under-reactivity (passivity) or over-reactivity while transition refers to the ease and consistency with which objects are withdrawn or to move from an activity to another, expressed as 'inflexible adherence to routines' in the DSM-5 [1]. Over-reactivity, under-reactivity and transition at 18 months discriminated EL-ASD from EL-TD and TL, as well as EL-TD from TL, and predicted ASD diagnosis at 36 months.

In parent questionnaires parents were asked about their child's surgency, positive affect, approach, activity, adaptability, effortful control and emotion regulation.

Parents identified abnormalities already during the first year and beginning of the second year. According to del Rosario et al. [56] through the CTS parents reported lower levels of approach (which stands for the tendency to approach new situations and people) at 6 months, of adaptability (as slowness to change behaviour in meeting the expectations of others) at 6 and 12 months, in EL-ASD than EL-TD. The trend changed across time with EL-ASD having higher score than EL-TD at 24 and 36 months in both approach and adaptability scales [56]. EL-ASD presented a less active behaviour (i.e. child is mainly engaged in many quieter pursuits) than EL-TD at 6 and 12 months, but differences were no longer significant across later development [56]. Similarly, in Zwaigenbaum et al. [33] through the IBQ and TBAQ parents described EL-ASD as having lower activity levels at 6 months than EL-TD and TL. Pijl et al. [35] confirmed above results, as they found through the ICBQ and ECBQ diverging levels of surgency (referring to engaging with environment, approach behaviours, positive affect and activity levels) from 8 to 14 months in EL-ASD as compared to EL-TD. Additionally, analyses from the TBAQ-R and the IBQ-R revealed that EL-ASD showed less effortful control (as the (in)ability to inhibit a dominant response) than EL-TD from 14 months, according to Pijl et al. [35], but not according to Garon et al. [57]. 
Zwaigenbaum et al. [27] reported parents' description of their EL-ASD children at 12 months as having more frequent and intense distress reactions (suggesting effortful attempts and difficulties to suppress emotions), less inhibitory control, less positive anticipation and affective responses than EL-TD and TL children. Lower positive affect at 12 months and effortful control at 24 months predicted ASD symptoms at 36 months [55].

Moving to the results from the 24-months-assessment, Garon et al. [57] found fewer approach behaviours at 24 months in EL-ASD than EL-TD and TL although normative levels at 24 months and 36 months were found by del Rosario et al. [56]. This trend of early impairment followed by later normalization was also found in del Rosario et al. [56] on the activity and adaptability scales. Finally, Garon et al. [57] reported higher scores on effortful emotion regulation at 24 months in EL than TL, while the two EL subgroups did not significantly differ.

\section{Discussion}

The present paper provides an overview of the early nonsocial behavioural indicators of ASD. The search was restricted to studies that allocated children at high risk for ASD in one of two classes of developmental outcome: diagnosis of ASD and typical development. In addition, differences between EL and TL children, as well as between EL-ASD and EL children with developmental delay (ELOther), are reported. We were particularly keen on exploring the developmental moment in which the differences among groups are first exhibited. Findings are clear for some domains while still conflicting for others. We described a characteristic as impaired in EL-ASD, when concordant results came from the majority of the studies assessing that domain, and always at least two studies, coming from different research groups. Results that are based on a single study should be interpreted with greater caution.

\section{Earliest non-social precursors of ASD: attention disengagement, fine and gross motor milestones, repetitive/stereotyped behaviour}

There is sufficient evidence in the review to state that EL children with later ASD are characterised by early impairments in attention disengagement, in gross and fine motor development, as well as characteristic restricted and repetitive interests and behaviours and atypical sensory experiences, compared to EL children with a typical developmental outcome. This pattern discriminates EL from TL children already between 6 and 12 months. From the 12th month and throughout the second year the aforementioned pattern differentiates between EL-ASD and EL-TD. Moreover, early attention disengagement appears to have a predictive role towards later ASD diagnosis, as documented by three studies [31-33]. The same conclusion was reached by single studies for several other domains (visual search, visual tracking, motor control, repetitive behaviour, sensory processing, temperament), but these findings need to be replicated.

\section{Attention}

Different theoretical models offer alternative interpretations of the results on attention disengagement. Landry and Bryson [15], for example, adduced to the potential role of domain-general processes in producing some of the core features of autism. According to this hypothesis, attention disengagement is a basic component of the orienting network, and is supposed to be important for the regulation of emotional states and for an appropriate social interaction. Analogue connection is present at an anatomic level, as the orienting network is closely connected to the arousal or vigilance network [78]. Thus, a dysfunction in a basic processsuch as attention disengagement-might underlie some of the core symptoms of ASD, including the social interaction and communication deficit, since orienting towards another stimulus (in this case another person) is a prerequisite for it. Alternatively, Bedford et al. [31] interpreted the simultaneous presence of attention disengagement and gaze following in EL-ASD at 13 months in light of a cascade (or additive) risk model, suggesting that measures of social and non-social attention contribute to ASD outcome via separate pathways. Contrary to disengagement, attention shift and engagement seem to be preserved in EL children [32, 33, 59].

If we consider disengagement, shift and engagement as three interrelated, but independent subcomponents of visual orienting, attention disengagement serves to relieve the visual system and allows it to reorient towards a salient target in the visual scene. While reaction time to disengage seems longer in EL-ASD, it might not affect the ability to orient towards a non-social stimulus, which seems to be preserved. Results in this direction have been confirmed by other studies $[32,51]$. On the contrary, several studies that found deficits in both attention disengagement and shift in children with ASD did not provide an independent measure of the two operations [60, 79-81].

Alternatively, we might adduce the absence of significant results in the present review to the small sample sizes [29, 62]. Noteworthy is the finding of Sacrey et al. [62] in which EL-ASD at 12 months were more likely to maintain their gaze on the toy after it was grasped, as well as to disengage and re-engage the toy prior to grasping, compared to EL-TD and TL, although differences were no longer visible at 36 months. This over-focus of attention, together with the tendency to re-engage the same stimulus, have often been 
documented $[14,82,83]$ both in the social and non-social domain, and they have been explained as a deficit in redirecting attention towards new stimuli, once their attention is engaged.

To sum up "the reduced ability to disengage attention from a stimulus (after previously engaging it) is one of the most consistently found cognitive deficits in people with ASD from infancy onwards" [84].

\section{Gross and fine motor milestones}

Delays and atypicalities in motor milestones have been a recurrent finding in infant studies on ASD and were already recognized by Kanner [85] and Asperger [86]. Unlike the literature on attention disengagement, opposite results have also been documented [87]. However, and compared to Ozonoff et al. [87], we attempted to give a closer focus on the developing motor system by highlighting several subdomains. According to the present review, at 6 months the Fine motor scale discriminated EL versus TL, but no differences within the EL group could be identified [26, 41, 42, 47]. The Gross motor scale did not discriminate EL from TL children during the first year $[42,64]$ and in two studies a TL group was missing [41, 47]. Noteworthy, Estes et al. [26] reported that a subgroup of EL children with later diagnosis of autism (EL-Autism) showed impaired gross motor development already at 6 months, compared to TL. It is from the second year that EL-ASD showed lower scores than EL-TD in Gross and Fine motor scales [41, 42, 47]. These data are particularly informative of the developmental trajectories of EL-ASD children. While early gross motor milestones (i.e. walking) are generally acquired at expected ages in EL children, more complex and fine motor skills hardly emerge. Accordingly, we can hypothesize a developmental decline between 14 and 24 months, a period in which EL-ASD children might be particularly vulnerable. A possible explanation was proposed by Akshoomoff et al. [88]. They stated that the brain volume of young EL-ASD is likely to begin in the typical range, and becomes larger than that of controls as early as at 6 months [89], but certainly by $2-4$ years [90]. Wolff et al. [91] found higher fractional anisotropy of white preceding matter tract in EL-ASD than EL-TD from 6 months until 24 months. It is noteworthy that the onset of white matter tract differences is consistent with the differences in gross motor development, both observed at 6 months. This process of pejorative neurobehavioural alteration starts very early and might explain the finding of Estes et al. [26] of impaired gross motor development of EL children with an autism outcome already at 6 months, with earlier and more severe deficits in children whose ASD symptoms are later more severe.

\section{Restricted and repetitive behaviours}

Results on this domain are particularly promising, as EL-ASD showed atypical repetitive interests and body movements compared to EL-TD already in the first year (6-12 months, Brian et al. [46], 12 months, Elison et al. [51]) and repetitive/stereotyped behaviours from 18 months, emerging coherently from parent reports [19] and standardized instruments within laboratory conditions [50].

The present results are in line with the acknowledgement of restricted and repetitive behaviours as a core symptom of ASD $[1,92]$. On the contrary, the question of why repetitive and restricted behaviours are consistent in people with ASD has received far less attention. In their systematic review, Leekam et al. [25] attempted to summarize the literature of the last 15 years on the neurobiological, developmental and cognitive influences that evoke RRBs. Among the potential candidate factors, a neurobiological explanation $[93,94]$ proposes that RRBs are the outcome of genetic vulnerability (chromosomal mutations). Support for genetic involvement in RRBs has been confirmed by more recent reviews [95-97]. Additionally, RRBs have proved to be an outcome of experiential deprivation or restriction [23]. Finally, both genetic and environmental evidence comes from mouse models and should be confirmed in studies on human populations.

Neuropsychological approaches propose a connection between executive functions and RRBs [98, 99]. However, the nature of the association between cognitive dysfunctioning and repetitive behaviour misses some clear evidence, due to the mixed nature of the results. Finally, the developmental psychology model (first proposed by Thelen [100]) postulates that RRBs are immature behavioural responses that are normal in young children with a typical development but restricted to an early period in children's lives, as they come increasingly under voluntary control as infants begin to develop goal-directed actions. Possible triggers for RRBs in ASD have also been identified in emotional and motivational states [101, 102].

\section{Relation between deficit in attention, motor milestones and repetitive/stereotyped behaviour}

Little is known about the relationship between attention and motor deficits in ASD. Ravizza et al. [103] described three alternative models: the resource allocation model assumes that attention impairment reduces other mental resources, producing impairments in other, non-affected domains (i.e. motor domain). The shared process model hypothesizes an impairment in a shared process, common to attention and motor domains. The independent account model assumes the absence of a core impairment able to explain both attention and motor deficits. Ravizza et al. [103] found that orienting 
attention was related to motor performance. However, the degree to which participants improved on the attention task when the motor demands were reduced was unrelated to the participants' performance on the motor task. Indeed, a shared process model seems to better explain the findings, compared to a resource allocation process. Confirmations come from identified anatomical abnormalities. Parietal lobe and the cerebellum are both associated with attention and motor coordination, and seem to be implicated in the neuropathology associated with ASD [104]. Furthermore, the authors found a significant correlation between the severity of stereotyped movements and motor control, while no direct link was found between orienting attention and RRBs.

\section{Preliminary results from other non-social behaviours: sensory atypicalities, social attention, play and temperament}

The present review leaves some open questions. No final conclusion was reached within the sensory domain, due to the heterogeneity of the sensory subcomponents assessed in each study. Similarly, the mentioned studies on temperament, although promising, need to be confirmed. Furthermore, the well-documented deficit in processing social stimuli in ASD was disconfirmed in the present review. Consequently, more research is needed to deepen alternative theoretical models. Finally, no conclusion about early atypical play behaviour could be achieved.

\section{Sensory domain}

Parents' concerns towards atypical sensory interests in ELASD have been documented from 6 months on by Sacrey et al. [19], compared to parents of EL-TD and TL (who did not differ). Similarly, the use of body and play materials in a self-stimulatory way at 12 months was predictive towards ASD [33]. In Germani et al. [44] sensory abnormalities at 24 months in EL-ASD were limited to the auditory domain, while Wolff et al. [53] extended them to all sensory domains. These results might suggest that sensory atypicalities might be a specific trait for children who develop ASD not seen at a sub-threshold level.

However, opposite results were presented by Brian et al. [72] in which EL-ASD and EL-TD did not differ in atypical sensory behaviour at any time point, while sensory behaviours were able to discriminate EL versus TL at 18 months. In line with this finding, Watson et al. [105] found that EL children with later developmental atypicalities but not ASD were rated higher by their parents on the sensory processing cluster compared to children with typical development.

The inconclusiveness of these results, with the exception of anomalies within the auditory domain reported by two studies, has also been documented elsewhere. In a recent review by Johnson et al. [106] sensory atypicalities were documented in $90 \%$ of children who already received a diagnosis of ASD. On the contrary, the sensory domain is still understudied in young children at risk for the disorder.

A possible explanation might be the difficulty in characterising sensory difficulties in a strongly empirical manner, compared to more apparent social and cognitive symptoms. Coherently, although the unusual sensory responses have been noted since the first clinical descriptions of autism, they have been included in the diagnostic criteria for the disorder only very recently [1].

\section{Social attention}

Results from studies on face processing without social interaction interestingly show that EL fixate faces longer than TL [20,37], or have a preference for local elements when processing visual stimuli (both social and non-social [107, 108]), findings that are possibly consistent with an emerging overly focal attention style. It should however be noted that only in one study this finding-prolonged looking time at faces-was actually related to the ASD outcome [37]. More studies should explore other measures of visual behaviour to test the hypothesis of a specific visual deficit towards social stimuli in children who later develop ASD. If replicated, the findings presented above would contradict models on ASD which assume less engagement with faces in ASD [109], but are consistent with Falck-Ytter et al. [40] and a growing body of research stating the absence of a deficit in early orienting specific to social stimuli (i.e. people, faces $[109,110]$ ).

\section{Play}

Parents of EL-ASD reported atypical play behaviour at 9 months compared to EL-TD and TL [19]. This result is consistent with previous findings of play impairments early in development $[111,112]$ and suggests that children with later ASD interact with and explore the environment in a way that is atypical very early during development.

Although further replication is needed, these and other results argue for a renewed attention to the content and timing of parental concerns.

\section{Temperament}

Put together, studies reporting parents' description outlined an early temperament profile of EL-ASD characterised by difficulties in approaching new people and situations, in changing behaviour according to people's expectations, lower levels of activity, already at 6 months, compared to EL-TD. This pattern was accompanied by more frequent and intense distress reactions, less positive affect and less inhibitory control at 12 months. Similar findings have been 
documented by Visser et al. [113] in their systematic review. Altogether, results push for a closer focus on temperament subcomponents, considering that the actual research on temperament in pre-school years is virtually non-existent and limited by the retrospective nature of most observations.

\section{Relationship between motor development and play}

While the review suggests the importance to look at motor skills early during child development of EL children, fundamental motor skills are also crucial for the future development of efficient active play. Research has demonstrated that proficiency in fundamental motor skills is positively associated with physical activity, which is expressed in the form of active play in young children. With movement being a core element of play, the motor delay experienced in children with later diagnosis of ASD might have negative consequences for play in this population. More in detail, it has been hypothesized that ASD children are not physically able to engage in active play, due in part to their poor motor skills [114]. Structural and functional neuroimaging studies confirm such a close connection. In particular, they have shown that the cerebellum is a key structure, not only for sensorimotor control, but also for higher level functions, such as cognition and emotions, all three being relevant in play behaviour through the connections with cortical (premotor, prefrontal and posterior parietal) areas, and that various cerebellar dysfunctions are highly correlated with deficits in sensorimotor play, repetitive behaviours, cognition and affect in ASD [115]. In line with above, a few studies have explored the effects of motor skills' interventions on adaptive skills, including object manipulation and object control during play $[116,117]$. The inconsistency of the results drives for a further investigation with larger samples and longer follows-up to better understand the impact of the intervention, and its intensity, on play skills retention.

\section{Relationship between temperament and sensory abnormalities}

Of particular interest is also the potential association between temperament and sensory features in ASD. Brock et al. [118] linked extreme sensory features to lower levels of approach and higher levels of distractibility. First, more extreme sensory features were linked to reduced approach towards novel physical or social events. For instance, a child with ASD who is hyporesponsive, may not attend to a new sensory stimulus in the environment and would be less likely to approach that stimulus. On the other hand, a child with ASD who is hyperresponsive might approach less to avoid an aversive sensory response. Although distractibility was not included in the present review as a temperament subcomponent, it has been deepened within the attention domain. Brock et al. [118] found that hyporesponsiveness was most associated with distractibility. One explanation is that children who are less responsive to sensory stimuli may simply be more difficult to distract. Alternatively, some children with ASD who are hyporesponsive may be difficult to engage at all, or may be overfocused on irrelevant stimuli and have trouble disengaging attention [31].

Finally, it should be noted that visual search, motor control and atypical motor behaviour fell within the early signs of ASD, but results were based on a single study, for each domain, thus preventing strong conclusions to be reached.

\section{General discussion: delineating the non-social behavioural profile of EL-ASD}

For the sake of readability, results from each non-social domain have been presented independently. Now, summing up, the review offers enough elements to delineate a profile of an EL child that could possibly receive a diagnosis of ASD at 36 months or later. Manifestations and time of symptoms' appearance are clear for some domains, but are uncertain for others.

Preliminary results based on single studies reported that parents described EL-ASD between 6 and 12 months as having a peculiar temperamental profile, atypical play skills as well as sensory abnormalities. Similarly, different assessment methods showed stereotypic interests in EL-ASD at the same time point.

A replicated, more robust finding is a temporal overlap in the appearance of some attention and motor deficits in EL children during the first year and in EL-ASD from 12 months on. Slower disengagement of attention and less mature fine motor behaviours clearly characterised EL as compared to TL between 6 and 12 months. By the end of the first year and during the second year EL-ASD showed atypical attention disengagement, abnormal fine and gross motor development, that discriminate them from EL-TD. Functional neuroimaging studies stated that abnormal integrity in the white matter in several brain regions has been found in young children with autism. It has been hypothesized that age, and thus the timing of white matter disruptions in the autistic brain, is particularly relevant $[119,120]$. Recent findings led to hypothesize that the last part of the first year of life could be a crucial time for anatomical changes in the brain of children who will later be diagnosed with ASD [121]. The concurrent timing with the ASD symptoms' onset suggests that brain changes from six months on may have an important role to the pathogenesis of autism behaviour [87] and could also explain the first months of relatively typical postnatal development in ASD. In addition, atypical patterns of connectivity are not specific to any single brain region, or behavioural domain, thus offering a potential explanation of the simultaneous appearance of multiple abnormalities at 
once. Overall, these data suggest the existence of a period of critical importance to the pathogenesis of ASD and reinforce the importance of a developmental approach to brain and behavioural changes during this time.

\section{Implications for clinical practice}

Put together, these findings show the progress made towards an earlier referral of ASD. Accordingly, they also offer new challenges to clinical practice.

Over the past two decades, ASD diagnostic instruments have been refined to offer a valuable source of information about a child that can help clinicians make better-informed judgments. Among them, the Autism Diagnostic Interview-Revised (ADI-R; [122]) and the Autism Diagnostic Observation Schedule 2 (ADOS-2; [123]) were developed to operationalize the core symptoms of ASD. These measures provide a standardized observation of current socialcommunicative behaviour, with excellent inter-rater reliability, internal consistency and test-retest reliability [66, 124]. However, an expert clinical view has shown to be more accurate than the use of standardised assessment instruments and the strict application of diagnostic criteria [123].

In line with the present findings, a piece of the puzzle seems to be missing from the current ASD diagnostic indications. Firstly, not only social-communication deficits, but also motor and attention abnormalities systematically characterize EL-ASD children compared to EL-TD, by the time in which the clinical diagnosis is applied. This finding should result in a new clinical approach to ASD, in which, through renewed diagnostic instruments, expert clinical judgment encompasses cognitive, motor and social anomalies.

Secondly, non-social abnormalities appear much before social impairments are fully manifest. Indeed, attention and motor deficits discriminate EL from TL from 6 months on, in line with parents' reports but also empirical screening measures. This result suggests the need for a new attitude towards the identification of ASD, in which a careful expert eye will recognise atypicalities in the first stages of cognitive and motor development. On the contrary, the absence of early social deficits cannot guarantee the exclusion of the risk for the later appearance of the clinical condition. Coherently, there seems to be some evidence that screening for ASD in children where an early developmental concern was already identified, may result in better sensitivity and specificity [125, 126].

Thirdly, the ability of non-social signs to discriminate between groups increases with age. From 12 months ELASD show distinct attention and motor impairments, compared to EL-TD. This last finding suggests that, rather than being indicators of general developmental delay, non-social impairments are specific for ASD.

Overall, the present findings urge for a multidisciplinary approach to the diagnostic assessment. Primary healthcare practitioners should directly elicit and note examples of characteristic social and non-social behaviours from parental report and where possible from direct observations. Parents' early concerns about motor development, distractibility, repetitive interests and behaviours should be considered as possible indicators of ASD, that warrant further monitoring. If these behaviours persist, then referral to a child development specialist for further assessment is strongly advised. In this context, screening should be implemented at regular intervals, ideally from children's first birthday [127].

Finally, equally relevant are the implications for therapeutic interventions. Several studies have shown that targeted interventions improve the outcome of children with ASD (see Dawson and Burner [128], LeBlank and Gillis [129], Zwaigenbaum et al. [130] for reviews). The co-presence of such diverse symptoms would recall for a combination of targeted interventions, intended to retrieve each impaired domain. Moreover, the enactment of early intervention would be a natural prosecution of the clinical profile emerged from these data. Despite the absence of direct empirical evidence that early compared to late interventions have a specific advantage, general consensus exists on the concept of early interventions supported by developmental principles.

\section{Limitations and directions for future research}

The absence of frequent repeated assessments of non-social precursors, with many studies not including any evaluation between 6 and 12 months, or between 12 and 24 months, represents a potential limit of the present review. Additionally, we report studies in which ASD diagnosis is based exclusively on instruments that identify socio-communicative deficits and repetitive behaviours, but leave several domains underexplored. Furthermore, the studies do not follow children up after their third birthday and therefore give no information on the stability of the diagnosis.

The acknowledgement of the increased prevalence of ASD in siblings of individuals with the same diagnosis represents an important facilitation for the systematic study of this clinical condition. The creation of databases of EL of ASD families in each country would facilitate the recruitment of participants for future research and favour the implementation of bigger surveys.

Overall, the finding of early detection of non-social symptoms and their stability across time suggests the need to systematically search for precursors long before the diagnosis can 
be implemented. Consequently, ASD should be reconsidered as an impairment of neurodevelopment that emerges gradually. Underdeveloped motor milestones, systematic difficulties in directing attention towards new stimuli and repetitive and stereotyped interests and behaviours are red flags for autism and should be addressed as specific precursors of ASD.

Parents' descriptions of everyday activities and observations of interactions with peers should be maintained in future studies because they uncover singular behaviours and atypical reactions to changes in the environment that are meaningful for characterising the ASD spectrum.

Finally, future studies will need to assess if and how the various non-social behaviours are interrelated and their connections at a neurocognitive level. A more comprehensive vision of early ASD precursors could result from the inclusion of early social and non-social precursors as well as its reciprocal relations.

Acknowledgements Open Access funding provided by Projekt DEAL. This study was funded by The Autism Spectrum Disorders in the European Union project (ASDEU). The ASDEU project has been granted by DG-SANTÉ, European Commission [Grant number SANCO/2014/ C2/035].

\section{Compliance with ethical standards}

Conflict of interest The authors declare that they have no conflict of interest.

Open Access This article is licensed under a Creative Commons Attribution 4.0 International License, which permits use, sharing, adaptation, distribution and reproduction in any medium or format, as long as you give appropriate credit to the original author(s) and the source, provide a link to the Creative Commons licence, and indicate if changes were made. The images or other third party material in this article are included in the article's Creative Commons licence, unless indicated otherwise in a credit line to the material. If material is not included in the article's Creative Commons licence and your intended use is not permitted by statutory regulation or exceeds the permitted use, you will need to obtain permission directly from the copyright holder. To view a copy of this licence, visit http://creativecommons.org/licenses/by/4.0/.

\section{References}

1. American Psychiatric Association (2013) Diagnostic and statistical manual of mental disorders (DSM- $5^{\circledR}$ ). American Psychiatric Pub

2. Rice C (2009) Prevalence of autism spectrum disorders-Autism and Developmental Disabilities Monitoring Network, United States, 2006. Morbidity and Mortality Weekly Report 58:SS-10

3. Baio J, Autism and Developmental Disabilities Monitoring Network Surveillance Year 2010 Principal Investigators (2014) Prevalence of autism spectrum disorder among children aged 8 years-autism and developmental disabilities monitoring network, 11 sites, United States 2010. MMWR Surveill Summ 63:1-21

4. Ozonoff S, Young GS, Carter A, Messinger D, Yirmiya N, Zwaigenbaum L, Bryson S, Carver LJ, Constantino JN, Dobkins
K, Hutman T (2011) Recurrence risk for autism spectrum disorders: a baby siblings research consortium study. Pediatrics 128:e488-e495

5. Geschwind DH (2011) Genetics of autism spectrum disorders. Trends Cognit Sci 15:409-416

6. Barbaro J, Dissanayake C (2009) Autism spectrum disorders in infancy and toddlerhood: a review of the evidence on early signs, early identification tools, and early diagnosis. J Dev Behav Pediatr 30:447-459

7. Mandell DS, Novak MM, Zubritsky CD (2005) Factors associated with age of diagnosis among children with autism spectrum disorders. Pediatrics 116:1480-1486

8. Daniels AM, Mandell DS (2014) Explaining differences in age at autism spectrum disorder diagnosis: a critical review. Autism 18:583-597

9. Chawarska K, Paul R, Klin A, Hannigen S, Dichtel LE, Volkmar F (2007) Parental recognition of developmental problems in toddlers with autism spectrum disorders. J Autism Dev Disord 37:62-72

10. Osterling JA, Dawson G, Munson JA (2002) Early recognition of 1 -year-old infants with autism spectrum disorder versus mental retardation. Dev Psychopathol 14:239-251

11. Baranek GT (1999) Autism during infancy: a retrospective video analysis of sensory-motor and social behaviors at 9-12 months of age. J Autism Dev Disord 29:213-224

12. Johnson CP (2008) Recognition of autism before age 2 years. Pediatr Rev 29:86

13. Baron-Cohen S, Leslie AM, Frith U (1985) Does the autistic child have a "theory of mind"? Cognition 21:37-46

14. Dawson G, Meltzoff AN, Osterling J, Rinaldi J, Brown E (1998) Children with autism fail to orient to naturally occurring social stimuli. J Autism Dev Disord 28:479-485

15. Landry R, Bryson SE (2004) Impaired disengagement of attention in young children with autism. J Child Psychol Psychiatry 45:1115-1122

16. Inui T, Kumagaya S, Myowa-Yamakoshi M (2017) Neurodevelopmental hypothesis about the etiology of autism spectrum disorders. Front Hum Neurosci 11:354

17. Elsabbagh M, Johnson MH (2010) Getting answers from babies about autism. Trends Cogn Sci 14:81-87

18. Yirmiya N, Charman T (2010) The prodrome of autism: early behavioral and biological signs, regression, peri-and postnatal development and genetics. J Child Psychol Psychiatry $51: 432-458$

19. Sacrey LA, Zwaigenbaum L, Bryson S, Brian J, Smith IM, Roberts W, Szatmari P, Roncadin C, Garon N, Novak C, Vaillancourt T (2015) Can parents' concerns predict autism spectrum disorder? A prospective study of high-risk siblings from 6 to 36 months of age. J Am Acad Child Adolesc Psychiatry 54:470-478

20. Rogers SJ (2009) What are infant siblings teaching us about autism in infancy? Autism Research 2:125-137

21. Zwaigenbaum L, Bryson S, Garon N (2013) Early identification of autism spectrum disorders. Behav Brain Res 251:133-146

22. Jones EJ, Gliga T, Bedford R, Charman T, Johnson MH (2014) Developmental pathways to autism: a review of prospective studies of infants at risk. Neurosci Biobehav Rev 39:1-33

23. Sacrey LA, Armstrong VL, Bryson SE, Zwaigenbaum L (2014) Impairments to visual disengagement in autism spectrum disorder: a review of experimental studies from infancy to adulthood. Neurosci Biobehav Rev 47:559-577

24. Downey R, Rapport MJ (2012) Motor activity in children with autism: a review of current literature. Pediatr Phys Ther 24:2

25. Leekam SR, Prior MR, Uljarevic M (2011) Restricted and repetitive behaviors in autism spectrum disorders: a review of research in the last decade. Psychol Bull 137:562 
26. Estes A, Zwaigenbaum L, Gu H, John TS, Paterson S, Elison JT, Hazlett H, Botteron K, Dager SR, Schultz RT, Kostopoulos $P$ (2015) Behavioral, cognitive, and adaptive development in infants with autism spectrum disorder in the first 2 years of life. J Neurodev Disord 7:24

27. Nickel TL, Thatcher AR, Keller F, Wozniak RH, Iverson JM (2013) Posture development in infants at heightened versus low risk for autism spectrum disorders. Infancy 18:639-661

28. Darcy-Mahoney A, Minter B, Higgins M, Guo Y, Williams B, Zauche LMH, Birth K (2016) Probability of an autism diagnosis by gestational age. Newborn Infant Nurs Rev 16:322-326

29. Gammer I, Bedford R, Elsabbagh M, Garwood H, Pasco G, Tucker L, Volein A, Johnson MH, Charman T, Team BASIS (2015) Behavioural markers for autism in infancy: scores on the Autism Observational Scale for Infants in a prospective study of at-risk siblings. Infant Behav Dev 38:107-115

30. Peterson J, Welch V, Losos M, Tugwell P (2011) The NewcastleOttawa scale (NOS) for assessing the quality of nonrandomised studies in meta-analyses. Ottawa Hospital Research Institute, Ottawa

31. Bedford R, Pickles A, Gliga T, Elsabbagh M, Charman T, Johnson MH, Team BASIS (2014) Additive effects of social and nonsocial attention during infancy relate to later autism spectrum disorder. Dev Sci 17:612-620

32. Bryson S, Garon N, McMullen T, Brian J, Zwaigenbaum L, Armstrong V, Roberts W, Smith I, Szatmari P (2018) Impaired disengagement of attention and its relationship to emotional distress in infants at high-risk for autism spectrum disorder. J Clin Exp Neuropsychol 40:487-501

33. Zwaigenbaum L, Bryson S, Rogers T, Roberts W, Brian J, Szatmari P (2005) Behavioral manifestations of autism in the first year of life. Int J Dev Neurosci 23:143-152

34. Wass SV, Jones EJ, Gliga T, Smith TJ, Charman T, Johnson MH, Baron-Cohen S, Bedford R, Bolton P, Chandler S, Davies K (2015) Shorter spontaneous fixation durations in infants with later emerging autism. Sci Rep 5:8284

35. Pijl MK, Bussu G, Charman T, Johnson MH, Jones EJ, Pasco G, Oosterling IJ, Rommelse NN, Buitelaar JK, Team BASIS (2019) Temperament as an early risk marker for Autism Spectrum Disorders? A longitudinal study of high-risk and low-risk infants. J Autism Dev Disord 3:1-2

36. Cheung $\mathrm{CH}$, Bedford R, Johnson $\mathrm{MH}$, Charman T, Gliga $\mathrm{T}$ (2018) Visual search performance in infants associates with later ASD diagnosis. Dev Cogn Neurosci 29:4-10

37. de Klerk CC, Gliga T, Charman T, Johnson MH (2014) Face engagement during infancy predicts later face recognition ability in younger siblings of children with autism. Dev Sci 17:596-611

38. Rutherford MD, Walsh JA, Lee V (2015) Brief report: infants developing with ASD show a unique developmental pattern of facial feature scanning. J Autism Dev Disord 45:2618-2623

39. Bedford R, Elsabbagh M, Gliga T, Pickles A, Senju A, Charman T, Johnson MH (2012) Precursors to social and communication difficulties in infants at-risk for autism: gaze following and attentional engagement. J Autism Dev Disord 42:2208-2218

40. Falck-Ytter T, Nystrom P, Gredeback G, Gliga T, Bolte S, Norin S, Konke LA, Brocki K, Cauvet E, Hedenius M, EASE team (2018) Reduced orienting to audiovisual synchrony in infancy predicts autism diagnosis at 3 years of age. J Child Psychol Psychiatry 59:872-880

41. Landa RJ, Gross AL, Stuart EA, Bauman M (2012) Latent class analysis of early developmental trajectory in baby siblings of children with autism. J Child Psychol Psychiatry 53:986-996

42. Libertus K, Sheperd KA, Ross SW, Landa RJ (2014) Limited fine motor and grasping skills in 6-month-old infants at high risk for autism. Child Dev 85:2218-2231
43. Kaur M, Srinivasan SM, Bhat AN (2015) Atypical object exploration in infants at-risk for autism during the first year of life. Front Psychol 6:798

44. Germani T, Zwaigenbaum L, Bryson S, Brian J, Smith I, Roberts W, Szatmari P, Roncadin C, Sacrey LA, Garon N, Vaillancourt $\mathrm{T}$ (2014) Brief report: assessment of early sensory processing in infants at high-risk of autism spectrum disorder. J Autism Dev Disord 44:3264-3270

45. St. John T, Estes AM, Dager SR, Kostopoulos P, Wolff JJ, Pandey J, Elison JT, Paterson SJ, Schultz RT, Botteron K, Hazlett H (2016) Emerging executive functioning and motor development in infants at high and low risk for autism spectrum disorder. Front Psychol 7:1016

46. Brian J, Bryson SE, Garon N, Roberts W, Smith IM, Szatmari P, Zwaigenbaum L (2008) Clinical assessment of autism in highrisk 18-month-olds. Autism 12:433-456

47. Landa R, Garrett-Mayer E (2006) Development in infants with autism spectrum disorders: a prospective study. J Child Psychol Psychiatry 47:629-638

48. Choi B, Leech KA, Tager-Flusberg H, Nelson CA (2018) Development of fine motor skills is associated with expressive language outcomes in infants at high and low risk for autism spectrum disorder. J Neurodev Disord 10:14

49. Sacrey LA, Zwaigenbaum L, Bryson S, Brian J, Smith IM (2018) The reach-to-grasp movement in infants later diagnosed with autism spectrum disorder: a high-risk sibling cohort study. J Neurodev Disord 10:41

50. Chawarska K, Shic F, Macari S, Campbell DJ, Brian J, Landa R, Hutman T, Nelson CA, Ozonoff S, Tager-Flusberg H, Young GS (2014) 18-month predictors of later outcomes in younger siblings of children with autism spectrum disorder: a baby siblings research consortium study. J Am Acad Child Adolesc Psychiatry 53:1317-1327

51. Elison JT, Wolff JJ, Reznick JS, Botteron KN, Estes AM, Gu H, Hazlett HC, Meadows AJ, Paterson SJ, Zwaigenbaum L, Piven J (2014) Repetitive behavior in 12-month-olds later classified with autism spectrum disorder. J Am Acad Child Adolesc Psychiatry 53:1216-1224

52. Damiano CR, Nahmias A, Hogan-Brown AL, Stone WL (2013) What do repetitive and stereotyped movements mean for infant siblings of children with autism spectrum disorders? J Autism Dev Disord 43:1326-1335

53. Wolff JJ, Dimian AF, Botteron KN, Dager SR, Elison JT, Estes AM, Network IBIS (2019) A longitudinal study of parentreported sensory responsiveness in toddlers at-risk for autism. J Child Psychol Psychiatry 60:314-324

54. Christensen L, Hutman T, Rozga A, Young GS, Ozonoff S, Rogers SJ, Baker B, Sigman M (2010) Play and developmental outcomes in infant siblings of children with autism. J Autism Dev Disord 1:946-957

55. Garon N, Zwaigenbaum L, Bryson S, Smith IM, Brian J, Roncadin C, Vaillancourt T, Armstrong V, Sacrey LA, Roberts W (2016) Temperament and its association with autism symptoms in a high-risk population. J Abnorm Child Psychol 44:757-769

56. del Rosario M, Gillespie-Lynch K, Johnson S, Sigman M, Hutman $T$ (2014) Parent-reported temperament trajectories among infant siblings of children with autism. J Autism Dev Disord 44:381-393

57. Garon N, Bryson SE, Zwaigenbaum L, Smith IM, Brian J, Roberts W, Szatmari P (2009) Temperament and its relationship to autistic symptoms in a high-risk infant sib cohort. J Abnorm Child Psychol 37:59-78

58. Elsabbagh M, Holmboe K, Gliga T, Mercure E, Hudry K, Charman T, Baron-Cohen S, Bolton P, Johnson MH, Team BASIS (2011) Social and attention factors during infancy and 
the later emergence of autism characteristics. Prog Brain Res 189:195-207

59. Elsabbagh M, Fernandes J, Webb J, Dawson SJ, Charman G, Johson T, British Autism Study of Infant Siblings Team (2013) Disengagement of visual attention in infancy is associated with emerging autism in toddlerhood. Biol Psych 74:189-194

60. Elsabbagh M, Gliga T, Pickles A, Hudry K, Charman T, Johnson MH, Team BASIS (2013) The development of face orienting mechanisms in infants at-risk for autism. Behav Brain Res 251:147-154

61. Gliga T, Bedford R, Charman T, Johnson MH, Baron-Cohen S, Bolton P, Cheung C, Davies K, Liew M, Fernandes J, Gammer I (2015) Enhanced visual search in infancy predicts emerging autism symptoms. Curr Biol 25:1727-1730

62. Sacrey LA, Bryson SE, Zwaigenbaum L (2013) Prospective examination of visual attention during play in infants at highrisk for autism spectrum disorder: a longitudinal study from 6 to 36 months of age. Behav Brain Res 256:441-450

63. Iverson JM, Shic F, Wall CA, Chawarska K, Curtin S, Estes A, Gardner JM, Hutman T, Landa RJ, Levin AR, Libertus K (2019) Early motor abilities in infants at heightened versus low risk for ASD: a baby siblings research consortium (BSRC) study. J Abnorm Psychol 128:69

64. LeBarton ES, Landa RJ (2019) Infant motor skill predicts later expressive language and autism spectrum disorder diagnosis. Infant Behav Dev 54:37-47

65. Bryson SE, Zwaigenbaum L, McDermott C, Rombough V, Brian J (2008) The Autism Observation Scale for Infants: scale development and reliability data. J Autism Dev Disord 38:731-738

66. Lord C, Risi S, Lambrecht L, Cook EH, Leventhal BL, DiLavore PC, Pickles A, Rutter M (2000) The Autism Diagnostic Observation Schedule-Generic: a standard measure of social and communication deficits associated with the spectrum of autism. $\mathbf{J}$ Autism Dev Disord 30:205-223

67. Rothbart MK (1981) Measurement of temperament in infancy. Child Dev 52:569-578

68. Holmboe K, Fearon RP, Csibra G, Tucker LA, Johnson MH (2008) Freeze-Frame: a new infant inhibition task and its relation to frontal cortex tasks during infancy and early childhood. $\mathrm{J}$ Exp Child Psychol 100:89-114

69. Mullen EM (1995) Mullen scales of early learning. American Guidance Service Publishing (AGS), Circle Pines

70. Dunn W, Daniels DB (2002) Initial development of the infant/ toddler sensory profile. J Early Interv 25:27-41

71. Piaget J (1954) La construction du rel chez l'enfant Neuchtel [The Construction of Reality in the Child]. New York

72. Folio MK, Fewell R (2000) Peabody developmental motor scales: examininer's manual, 2nd edn. PRO-ED Inc, Austin

73. Wetherby AM, Morgan L (2007) Repetitive and stereotyped movement scales: companion to the CSBS. Unpublished manual Florida State University, Tallahassee

74. Baranek GT, David FJ, Poe MD, Stone WL, Watson LR (2006) Sensory Experiences Questionnaire: discriminating sensory features in young children with autism, developmental delays, and typical development. J Child Psychol Psychiatry 47:591-601

75. McDevitt SC, Carey WB (1996) Manual for the behavioral style questionnaire. Behavioral-Developmental Initiatives, Scottsdale

76. Goldsmith HH (1996) Studying temperament via construction of the Toddler Behavior Assessment Questionnaire. Child Dev 67:218-235

77. Putnam SP, Gartstein MA, Rothbart MK (2006) Measurement of fine-grained aspects of toddler temperament: The Early Childhood Behavior Questionnaire. Infant Behav Dev 29:386-401

78. Posner MI, Petersen SE (1990) The attention system of the human brain. Annu Rev Neurosci 13:25-42
79. Elsabbagh M, Volein A, Holmboe K, Tucker L, Csibra G, Baron-Cohen S, Bolton P, Charman T, Baird G, Johnson MH (2009) Visual orienting in the early broader autism phenotype: disengagement and facilitation. J Child Psychol Psychiatry 50:637-642

80. Renner P, Grofer Klinger L, Klinger MR (2006) Exogenous and endogenous attention orienting in autism spectrum disorders. Child Neuropsychol 12:361-382

81. Pruett JR, LaMacchia A, Hoertel S, Squire E, McVey K, Todd RD, Constantino JN, Petersen SE (2011) Social and non-social cueing of visuospatial attention in autism and typical development. J Autism Dev Disord 41:715-731

82. Harris NS, Courchesne E, Townsend J, Carper RA, Lord C (1999) Neuroanatomic contributions to slowed orienting of attention in children with autism. Brain Res Cognit Brain Res 8:61-71

83. Baranek GT, Watson LR, Boyd BA, Poe MD, David FJ, McGuire L (2013) Hyporesponsiveness to social and nonsocial sensory stimuli in children with autism, children with developmental delays, and typically developing children. Dev Psychopathol 25:307-320

84. Orekhova EV, Stroganova TA (2014) Arousal and attention reorienting in autism spectrum disorders: evidence from auditory event-related potentials. Front Hum Neurosci 8:34

85. Kanner L (1943) Autistic disturbances of affective contact. Nervous Child 2:217-250

86. Asperger H (1944) Die „Autistischen Psychopathen” im Kindesalter. ['Autistic psychopathy' in childhood.] Arch Psychiatr Nervenkr 117:76-136

87. Ozonoff S, Young GS, Goldring S, Greiss-Hess L, Herrera AM, Steele J, Macari S, Hepburn S, Rogers SJ (2008) Gross motor development, movement abnormalities, and early identification of autism. J Autism Dev Disord 38:644-656

88. Akshoomoff N, Pierce K, Courchesne E (2002) The neurobiological basis of autism from a developmental perspective. Dev Psychopathol 14:613-634

89. Courchesne E, Carper R, Akshoomoff N (2003) Evidence of brain overgrowth in the first year of life in autism. JAMA 290:337-344

90. Bartholomeusz HH, Courchesne E, Karns CM (2002) Relationship between head circumference and brain volume in healthy normal toddlers, children, and adults. Neuropediatrics 33:239-241

91. Wolff JJ, Gu H, Gerig G, Elison JT, Styner M, Gouttard S, Botteron KN, Dager SR, Dawson G, Estes AM, Evans AC (2012) Differences in white matter fiber tract development present from 6 to 24 months in infants with autism. Am J Psychiatry 169:589-600

92. World Health Organization (1993) The ICD-10 classification of mental and behavioural disorders: diagnostic criteria for research. World Health Organization

93. Lewis M, Kim SJ (2009) The pathophysiology of restricted repetitive behavior. J Neurodev Disord 1:114

94. Langen M, Durston S, Kas MJ, van Engeland H, Staal WG (2011) The neurobiology of repetitive behavior: of mice. Neurosci Biobehav Rev 35:356-365

95. Banerjee S, Bhat M, Riordan M (2014) Genetic aspects of autism spectrum disorders: insights from animal models. Front Cell Neurosci 8:58

96. Staal WG (2015) Autism, DRD3 and repetitive and stereotyped behavior, an overview of the current knowledge. Eur Neuropsychopharmacol 25:1421-1426

97. Griffiths KK, Levy RJ (2017) Evidence of mitochondrial dysfunction in autism: biochemical links, genetic-based associations, and non-energy-related mechanisms. Oxid Med Cell Longev Epub 
98. Prior M, Ozonoff S (2007) Psychological factors in autism. In: Volkmar F (ed) Autism and pervasive developmental disorders, 2nd edn. Cambridge University Press, Cambridge, pp 69-128

99. Zandt F, Prior M, Kyrios M (2007) Repetitive behaviour in children with high functioning autism and obsessive compulsive disorder. J Autism Dev Disord 37:251-259

100. Thelen E (1981) Rhythmical behavior in infancy: an ethological perspective. Dev Psychol 17:237

101. Barber AB (2008) The context of repetitive and stereotyped behaviors in young children with autism spectrum disorders: Exploring triggers and functions. Context. Electronic Theses, Treatises and Dissertations

102. Joosten AV, Bundy AC, Einfeld SL (2009) Intrinsic and extrinsic motivation for stereotypic and repetitive behavior. J Autism Dev Disord 39:521-531

103. Ravizza SM, Solomon M, Ivry RB, Carter CS (2013) Restricted and repetitive behaviors in autism spectrum disorders: the relationship of attention and motor deficits. Dev Psychopathol 25:773-784

104. Amaral DG, Schumann CM, Nordahl CW (2008) Neuroanatomy of autism. Trends Neurosci 31:137-145

105. Watson LR, Baranek GT, Crais ER, Reznick JS, Dykstra J, Perryman T (2007) The first year inventory: retrospective parent responses to a questionnaire designed to identify one-year-olds at risk for autism. J Autism Dev Disord 37:49-61

106. Johnson MH, Gliga T, Jones E, Charman T (2015) Annual Research Review: Infant development, autism, and ADHD-early pathways to emerging disorders. J Child Psychol Psychiatry $56: 228-247$

107. Freeseman LJ, Colombo J, Coldren JT (1993) individual differences in infant visual attention: four-month-olds' discrimination and generalization of global and local stimulus properties. Child Dev 64:1191-1203

108. Frick JE, Colombo J (1996) Individual differences in infant visual attention: recognition of degraded visual forms by four-montholds. Child Dev 67:188-204

109. Dawson G, Webb SJ, McPartland J (2005) Understanding the nature of face processing impairment in autism: insights from behavioral and electrophysiological studies. Dev Neuropsychol 27:403-424

110. Chevallier C, Kohls G, Troiani V, Brodkin ES, Schultz RT (2012) The social motivation theory of autism. Trends Cognit Sci 16:231-239

111. Landa RJ, Holman KC, Garrett-Mayer E (2007) Social and communication development in toddlers with early and later diagnosis of autism spectrum disorders. Arch Gen Psychiatry 64:853-864

112. Wetherby AM, Prizant BM (2002) Communication and symbolic behavior scales: developmental profile. Paul H Brookes Publishing, Baltimore

113. Visser JC, Rommelse NN, Greven CU, Buitelaar JK (2016) Autism spectrum disorder and attention-deficit/hyperactivity disorder in early childhood: a review of unique and shared characteristics and developmental antecedents. Neurosci Biobehav Rev 65:229-263

114. Gallo-Lopez L, Rubin LC (2012) Play-based interventions for children and adolescents with autism spectrum disorders. Routledge, Abingdon
115. D'Mello AM, Stoodley CJ (2015) Cerebro-cerebellar circuits in autism spectrum disorder. Front Neurosci 9:408

116. Bremer E, Balogh R, Lloyd M (2015) Effectiveness of a fundamental motor skill intervention for 4-year-old children with autism spectrum disorder: a pilot study. Autism 19:980-991

117. Ketcheson L, Hauck J, Ulrich D (2017) The effects of an early motor skill intervention on motor skills, levels of physical activity, and socialization in young children with autism spectrum disorder: a pilot study. Autism 21:481-492

118. Brock ME, Freuler A, Baranek GT, Watson LR, Poe MD, Sabatino A (2012) Temperament and sensory features of children with autism. J Autism Dev Disord 42:2271-2284

119. Alexander AL, Lee JE, Lazar M, Boudos R, DuBray MB, Oakes TR, Miller JN, Lu J, Jeong EK, McMahon WM, Bigler ED (2007) Diffusion tensor imaging of the corpus callosum in autism. Neuroimage 34:61-73

120. Keller TA, Kana RK, Just MA (2007) A developmental study of the structural integrity of white matter in autism. NeuroReport $18: 23-27$

121. Zachor DA, Curatolo P (2014) Recommendations for early diagnosis and intervention in autism spectrum disorders: an ItalianIsraeli consensus conference. Eur J Paediatr Neurol 18:107-118

122. Lord C, Rutter M, Le Couteur A (1994) Autism Diagnostic Interview-Revised: a revised version of a diagnostic interview for caregivers of individuals with possible pervasive developmental disorders. J Autism Dev Disord 24:659-685

123. Lord C, Rutter M, DiLavore P, Risi S, Gotham K, Bishop S (2012) Autism diagnostic observation schedule-2nd edition (ADOS-2). Western Psychological Corporation, Los Angeles

124. Luyster R, Gotham K, Guthrie W, Coffing M, Petrak R, Pierce K, Bishop S, Esler A, Hus V, Oti R, Richler J (2009) The Autism Diagnostic Observation Schedule-Toddler Module: a new module of a standardized diagnostic measure for autism spectrum disorders. J Autism Dev Disord 39:1305-1320

125. Charman T, Baird G (2002) Practitioner review: diagnosis of autism spectrum disorder in 2-and 3-year-old children. J Child Psychol Psychiatry 43:289-305

126. Charman T, Swettenham J (2001) Repetitive behaviors and social-communicative impairments in autism: implications for developmental theory and diagnosis. In: Burack JA, Charman T, Yirmiya N, Zelazo PR (eds) Development and autism: perspectives from theory and research. Lawrence Erlbaum Associates, New Jersey, pp 325-345

127. Robins DL, Fein D, Barton ML, Green JA (2001) The Modified Checklist for Autism in Toddlers: an initial study investigating the early detection of autism and pervasive developmental disorders. J Autism Dev Disord 31:131-144

128. Dawson G, Burner K (2011) Behavioral interventions in children and adolescents with autism spectrum disorder: a review of recent findings. Curr Opin Pediatr 23:616-620

129. LeBlanc LA, Gillis JM (2012) Behavioral interventions for children with autism spectrum disorders. Pediatr Clin N Am 59:147-164

130. Zwaigenbaum L, Bauman ML, Choueiri R, Kasari C, Carter A, Granpeesheh D, Mailloux Z, Roley SS, Wagner S, Fein D, Pierce K (2015) Early intervention for children with autism spectrum disorder under 3 years of age: recommendations for practice and research. Pediatrics 136:S60-81 